Federal Reserve Bank of Minneapolis

Research Department Staff Report 187

February 1995

\title{
Capacity Precommitment as a Barrier to Entry: A Bertrand-Edgeworth Approach*
}

\author{
Beth Allen \\ University of Minnesota \\ and Federal Reserve Bank of Minneapolis
}

\section{Tom Faith}

Tilburg University

\author{
Raymond Deneckere \\ University of Wisconsin
}

Dan Kovenock

Purdue University

\begin{abstract}
This paper considers the role of capacity as a strategic entry deterrent for a game in which the incumbent and entrant sequentially precommit to capacity levels before competing in price, possibly using mixed strategies. Depending on the magnitudes of the fixed set-up cost, the cost of capacity, and the relative costs of production, the model produces a wide spectrum of equilibrium behaviors, including some not previously suggested in the literature. Interesting deterrence effects occur because firms need time to build. In contrast to much previous work, the incumbent may hold idle capacity when entry is deterred.
\end{abstract}

*This paper was presented at the Midwest Mathematical Economics Conference in May 1991, the North American Winter Meetings of the Econometric Society in January 1992, and the European Meetings of the Econometric Society in August 1992 and in seminars at Erasmus University, the Katholieke Universiteit Leuven, the Pennsylvania State University, Purdue University, the Rijksuniversiteit Limburg, Tilburg University, the Universitat Autonoma de Barcelona, the University of Illinois, and Washington State University. Allen's research was partially supported by the National Science Foundation. Faith's work was supported by a David Ross Dissertation Grant at Purdue University and by funding from Erasmus University. Kovenock benefitted from the support of the Center for Economic Research at Tilburg University, the Tinbergen Institute, and the Jay N. Ross Young Faculty Scholar Award at Purdue University. The views expressed in this paper are those of the authors and not necessarily those of the Federal Reserve Bank of Minneapolis or the Federal Reserve System. 


\section{Introduction}

Most theories of the determinants of industrial concentration assign an important role to scale economies, at either the plant or the firm level. However, U.S. manufacturing appears to be considerably more concentrated than would be warranted by scale economies alone. For example, in nine of the twelve industries examined by Scherer et al. (1975), the market share of the top three firms in each industry ranges from two to ten times larger than the market share necessary to exploit scale economies (with an average of 4.4 over the whole sample). One possible explanation for this observed divergence is that strategic actions undertaken by incumbent firms can magnify the advantages conferred by scale economies. The literature on capacity as a strategic entry deterrent (surveyed below) advances such a theory: by building capacity in excess of what would be optimal in the absence of an entry threat, early incumbents can deter further entry, or at least reduce the scale of such entry.

This paper uses the Bertrand-Edgeworth model of price competition to reexamine the role of capacity precommitment as an entry deterring device. More precisely, we assume that there are two firms, an incumbent and a potential entrant (henceforth called the entrant), that compete in a market for a homogeneous good. The firms play a three-stage noncooperative game. First, the incumbent chooses its capacity. Having observed the incumbent's capacity level, the entrant then selects capacity. In the third stage, the firms simultaneously set prices.

Allen (1993) first analyzed a game of this type. Our paper differs from Allen's (1993) analysis in two important ways. ${ }^{1}$ First, we allow firms to have different unit costs of production up to capacity. This enables us to examine the role of differential efficiency in determining the nature of precommitment; with asymmetric efficiencies a firm may want to precommit to be large (as in Dixit (1980)) or small (as in Gelman and Salop (1983)). Second, we characterize the equilibrium for arbitrary (but identical) costs of capacity and fixed set-up costs. A central theme

\footnotetext{
${ }^{1}$ Allen (1993) shows that when firms are equally efficient, there exists a range of fixed costs over which the incumbent can profitably deter entry. However, the paper characterizes neither the optimal entry deterring strategy, nor the region over which deterrence is feasible or optimal. It is also mute on the nature of equilibrium when deterrence is either not feasible or not optimal.
} 
of our paper is that the distinction between fixed costs of entry, the cost of capacity, and the cost of production up to capacity is crucial to the understanding of a wide range of economic phenomena.

The contemporary analysis of entry deterrence can be seen as an outgrowth of the limit pricing model of Bain (1956), Sylos-Labini (1969), and Modigliani (1958). According to Bain (1956, p. 98), potential entrants act as if they expected that upon entry established firms would maintain output at the pre-entry level. ${ }^{2}$ The decision whether to enter the industry is therefore based upon a comparison of the residual demand curve (industry output minus the pre-entry output of incumbent firms) and potential entrants' cost conditions. If there are economies of scale in production, or if entrants are cost disadvantaged, established firms can raise their preentry output level up to the point where entry is effectively deterred. By its nature this framework compresses firms' long-run entry and size decisions and their short-run production and pricing decisions into the same period. Later models of entry deterrence (e.g., Dixit's (1979)) have formally separated these two decision periods and have argued that the threat to maintain output at the pre-entry level is not subgame perfect.

Our paper differs from most previous analyses of entry deterrence in its assumptions regarding competition in the post-entry game. Spence (1977) assumes that the post-entry game is perfectly competitive, i.e., that price clears all capacity from the market. Dixit (1980), Spulber (1981), Ware (1985), and Bulow, Geanakoplos, and Klemperer (1985) examine the case where the post-entry game is Cournot. Spulber (1981), Saloner (1985), and Basu and Singh (1990) examine entry when the post-entry game is Stackelberg quantity-setting.

Post-entry Bertrand competition has remained relatively neglected. Dixit (1980) and Bulow, Geanakoplos, and Klemperer (1985) examine Bertrand competition in the final stage in a differentiated products model. Bulow, Geanakoplos, and Klemperer $(1985$, p. 181) note that with homogeneous goods, final stage price-setting leads to marginal cost pricing and, therefore,

\footnotetext{
${ }^{2}$ This assumption has become known as the Sylos postulate.
} 
if the entrant's constant marginal costs are at least as great as the incumbent's and if there is a fixed cost of entry, "we would never expect to observe entry followed by price competition." 3 Our paper demonstrates that this conclusion is an artifact of a modelling strategy which allows capacity to be instantaneously adjusted upward in the post-entry game. Borrowing terminology from the real business cycles literature (see Kydland and Prescott (1982)), we call this assumption no time to build. This assumption is maintained in both the Dixit and the Bulow, Geanakoplos, and Klemperer models (as in most of the other models above). ${ }^{4}$ While its implications are innocuous for quantity-setting games, this is not true for post-entry price-setting, as noted by Edgeworth (1925). Our paper departs from these previous attempts to deal with post-entry price-setting by assuming that capacity requires time to build. Specifically, we assume that the incumbent and entrant may sequentially precommit to capacity levels. However, once these capacities are in place there is no upward adjustment in the post-entry stage. ${ }^{5}$ Prices are set subject to the limitations on sales imposed by the capacity constraints.

The Bertrand-Edgeworth approach to modelling post-entry competition is appealing for several reasons. First, it is immune to the Bertrand critique; firms set prices. This avoids the Cournot model's reliance on the hypothetical auctioneer who sets prices to clear quantities in the market. Moreover, for most markets a strong intuitive argument can be made that prices are more easily adjusted than quantities and hence can be set contingent on the quantities available. This leads naturally to a model where price formation is the final stage of a multistage game.

A common defense of the Cournot model is based on the Kreps and Scheinkman (1983) argument that simultaneous quantity choice followed by simultaneous price-setting can yield a

${ }^{3}$ This statement is supported by Stiglitz (1987) and is also attributed to Gilbert in the discussion following Gilbert (1986).

${ }^{4}$ More specifically, although neither paper is explicit about the timing; it is assumed that capacities can be adjusted upward after prices have been set.

${ }^{5}$ Ware (1985) also assumes that the incumbent and entrant sequentially precommit to capacity levels. However, he assumes post-entry Cournot competition and instantaneous adjustment of capacity at that time. 
Cournot outcome. ${ }^{6}$ However, there is a growing consensus among theoreticians that the choice of a quantity in the Cournot model should be interpreted as a level of capital investment or scale of operation. ${ }^{7}$ It therefore seems inappropriate to appeal to the Kreps-Scheinkman result to justify post-entry Cournot competition in a model in which capital may be precommitted. A more natural approach is to replace the Kreps and Scheinkman (1983) assumption of simultaneous capacity choice by sequential precommitment in the choice of capacity.

The Bertrand-Edgeworth approach to modelling post-entry competition also has another, hitherto largely unnoticed, advantage over the no time to build approach: when fixed entry costs are either nonexistent or not too large, the latter approach is incapable of generating a first-mover advantage from capacity precommitment . Indeed, consider Dixit's (1980) analysis, in which an incumbent (firm 1) and a potential entrant (firm 2) sell imperfect substitutes. After the incumbent chooses a capacity level $\mathrm{k}_{1}$, firm 2 decides whether or not to enter. In the event entry occurs, both firms simultaneously announce a price and expand capacity to satisfy any demand that can be profitably sold at these prices. ${ }^{8}$ The situation is depicted in Figure 1 . The two curves $\mathrm{MM}^{\prime}$ and $\mathrm{NN}^{\prime}$ represent the incumbent's best response functions, the former when capacity costs matter and the latter when capacity costs are sunk. The curve $\mathrm{EE}^{\prime}$ is the potential entrant's best-

${ }^{6}$ See, however, the work of Davidson and Deneckere (1986), who show that this result is sensitive to the choice of rationing rule, and Deneckere and Kovenock (1989b), who show that, even with the rationing rule used by Kreps and Scheinkman (1983), the equivalence need not hold with different unit costs of production up to capacity. Moreover, as Allen and Hellwig (1986) show, simultaneous price and quantity choices do not, in general, lead to Cournot outcomes under proportional rationing.

${ }^{7}$ For instance, Shapiro (1989), referring to Kreps and Scheinkman, states that "they take the view, to which I adhere, that capital is a relatively sluggish variable, whereas prices can be adjusted rapidly. This leads to a model of capacity competition followed by pricing competition." Tirole (1988, p. 218) puts it more forcefully when he states that "the two-stage game is meant to convey the idea that price competition is the final stage of competition and the idea that scale decisions must be made before firms arrive on the market.... what we mean by quantity competition is really a choice of scale that determines the firm's cost functions (sic) and thus determines the conditions of price competition." (Original italics)

${ }^{8}$ More precisely, the post-entry game is a differentiated products price-setting game where firm 2 has a constant marginal cost of $\left(c_{2}+r\right)$ for all levels of output, while firm 1 has a constant marginal cost equal to $c_{1}$ for output levels below $k_{1}$, and $\left(c_{1}+r\right)$ for output levels above $k_{1}$, where $r$ is the unit cost of capacity and $c_{1}$ and $c_{2}$ are the respective unit variable production costs. 
response function (where capacity costs still matter). In a simultaneous move price-setting game, the equilibrium would thus occur at the point $T$ in the diagram. However, because in the postentry stage the incumbent's capacity costs at output levels $\mathrm{x}_{1} \leq \mathrm{k}_{1}$ are effectively sunk, the incumbent's reaction function in the second stage of the two-stage game is $\mathrm{NN}^{\prime}$ for output levels $x_{1} \leq k_{1}$ and $M M^{\prime}$ for output levels $x_{1}>k_{1}$. The curve $x_{1}=k_{1}$ represents all $\left(p_{1}, p_{2}\right)$ combinations at which the incumbent's demand is equal to $\mathrm{k}_{1}$, i.e., where the incumbent is capacity constrained unless this firm expands beyond $k_{1}$. The overall best-response function of the incumbent in the post-entry game is therefore represented by the heavy line in Figure 1. With the choice of $k_{1}$ as depicted, the second-stage equilibrium would occur at $T^{\prime}$. By varying the preentry choice of $k_{1}$, the incumbent can secure any point along the segment TV of the potential entrant's best-response function. This leads Dixit (1980, p. 105) to mistakenly conclude that "a limited leadership possibility arise(s) by virtue of the established firm's advantage in being the first to make a commitment to capacity." Indeed, in the analogous quantity-setting game which he analyzes earlier, the leadership possibility is limited because the line segment TV may not include the Stackelberg point $S$. In that case $V$ is the incumbent's most preferred outcome. For the price-setting game, the Stackelberg point can be found by superimposing the incumbent's isoprofit contours onto Figure 1; see Figure 2. Since $\mathrm{S}$ lies to the right of $\mathrm{T},{ }^{9}$ the most preferred outcome on the segment TV now occurs at the duopoly point T. In contrast to Dixit, we conclude that in differentiated product price-setting games with no time to build, the ability to sink investment costs confers no strategic advantage on the incumbent. Intuitively, the incumbent would like to precommit to a capacity below the duopoly level in order to soften the post-entry competition. ${ }^{10}$ With no time to build, a commitment to restrict capacity to the Stackelberg level is not credible, and the best the incumbent can do is enjoy duopoly profits. It should also be emphasized that while the above result was derived under the assumption of zero

${ }^{9}$ At the point $T$, the first-order effect on the incumbent's profits of increasing $\mathrm{p}_{1}$ is zero, but the first-order effect of an increase in $\mathrm{p}_{2}$ is positive. Consequently $\mathrm{S}$ must be to the right of $\mathrm{T}$.

${ }^{10}$ This is the "puppy dog" effect emphasized by Fudenberg and Tirole (1984). 
fixed entry costs, the reasoning remains valid as long as the profits of firm 2 at the point $V$-net of fixed entry costs-are positive.

The Bertrand-Edgeworth approach to strategic entry deterrence is also appealing because of the array of qualitatively distinct outcomes that are generated as subgame perfect equilibria in the resulting game. Entry may be blockaded, deterred, or accommodated, depending on the configuration of costs. In cases where entry is successfully deterred, excessive capacity built to deter entry may be utilized completely or may be left partially idle. ${ }^{11}$ That is, the equilibrium price of the incumbent may or may not clear its entire production capacity from the market, depending on the cost parameters.

The existence of a subgame perfect equilibrium involving idle capacity to deter entry is of independent interest. While a number of models in the existing literature obtain idle capacity to deter entry, these models all rely on nonstandard assumptions concerning behavior or timing. Spence (1977) obtains idle capacity, but assumes that firms produce at full capacity in the postentry game. Such behavior can only be justified if the post-entry game is perfectly competitive, an assumption which seems at odds with the small number of competitors present in the market. Indeed, Dixit (1980) has argued that Spence's result arises because entrants believe noncredible threats regarding the incumbent's post-entry output. When an opponent enters the market, its increase in quantity or reduction in price produces an inward shift in the incumbent's residual demand curve. The incumbent then responds rationally by reducing its output. Consequently, any capacity that was idle before entry will remain idle after entry and so will not deter entry. Since capacity costs are positive, no rational incumbent will ever choose to install idle capacity. Bulow, Geanakoplos, and Klemperer (1985) regain idle capacity in an example in which only credible threats are believed. However, they require that the monopolist's residual demand function becomes sufficiently more elastic upon entry that its marginal revenue increases. This will make it rational for the incumbent to raise output in the post-entry game. However, upward

${ }^{11}$ By excessive capacity, we mean capacity that is built solely for strategic reasons, i.e., capacity in excess of the level a monopolist would choose were its market unchallenged. 
sloping portions in the quantity best-response function cannot occur for concave demand functions. Lastly, Spulber (1981) has demonstrated that idle capacity may result if the incumbent maintains its first-mover advantage beyond the capacity-setting period into the (postentry) output-setting period. ${ }^{12}$ Unlike any of the above papers, the present paper provides an explanation of why holding idle capacity to deter entry can be rational, while maintaining a postentry simultaneous move structure, subgame perfection, and standard assumptions about demand. In our model, idle capacity may prove useful because, in the mixed strategy equilibrium which results following entry, the incumbent only reduces output when it is undercut by the entrant. Whenever the incumbent is lower priced, it raises output, thereby partially utilizing idle capacity and reducing the entrant's expected profits.

When entry is accommodated in our model, the incumbent may behave according to the Sylos postulate, so that price is driven down to the level that clears all capacity, or the incumbent may provide a stochastic price umbrella under which the entrant can price. In the latter instance, the incumbent stochastically reduces output below capacity. ${ }^{13}$ Following Faith (1990) we provide conditions on the cost parameters that determine which strategy the incumbent follows. When prices clear production capacities, the classical Stackelberg equilibrium sometimes arises. In other cases, the outcome duplicates the equilibria in Dixit's (1980) quantity-setting model. When entry is accommodated by a (stochastic) reduction in output, the result may best be described as a simultaneous price-setting version of Gelman and Salop's (1983) "judo" equilibrium. The incumbent sets a large capacity, and the entrant remains small to discourage

${ }^{12}$ This method of generating idle capacity to deter entry was rediscovered by Basu and Singh (1990).

${ }^{13}$ When in equilibrium entry is successfully deterred, this type of behavior is also exhibited in off-the-equilibrium-path subgames following entry. When entry is deterred with excessive but not idle capacity, off-the-equilibrium-path post-entry behavior may involve either Sylos-like behavior or stochastic output reduction (below capacity). When idle capacity is held in deterring entry, off-the-equilibrium-path entry will involve only stochastic output reduction below capacity. 
intense price competition. ${ }^{14}$ By relating the existence of the Stackelberg and judo outcomes to the values of the cost parameters, our model provides a unifying framework in which these outcomes appear as special cases.

As is evident from the above discussion, the Bertrand-Edgeworth model is also of interest because of the wealth of testable implications that it generates. Not surprisingly, entry is accommodated when fixed set-up costs and differences in variable production cost (as measured by the unit costs of production up to capacity) are small. For high capacity costs, entry accommodation will result in Stackelberg behavior, while for low capacity costs, judo-like behavior with idle capacity will arise. Entry deterrence with excessive capacity tends to occur when the unit cost of capacity is not too large and there are moderate fixed set-up costs. ${ }^{15}$ In both situations in which entry is deterred and accommodated, idle capacity is more likely with a more efficient incumbent than with a less efficient one (as measured by unit cost of production up to capacity) and is more likely the lower the cost of capacity. Excessive (but fully utilized) capacity is more likely to be chosen as a preemptive strategy the higher the cost of capacity and the higher fixed set-up costs.

This list of testable implications is intended to be suggestive rather than exhaustive. The usefulness of the Bertrand-Edgeworth approach can be measured by the difficulty which other economically reasonable models of entry have in generating comparable predictions. Our model provides a cohesive and coherent framework which generates a range of equilibrium behaviors that depend on parameters in an intuitive way. Further extensions of the present model along the same lines as Cournot-based models of entry can undoubtedly lead to an even richer theory of market interaction. ${ }^{16}$

${ }^{14}$ This may occur even if the entrant is more efficient (see also Faith (1990)).

${ }^{15}$ When capacity costs are large, entry is more likely to be accommodated (if fixed set-up costs are small) or blockaded (if fixed set-up costs are large). The range of fixed set-up costs for which entry is deterred becomes small.

${ }^{16}$ One such extension is Hunsaker's (1993) treatment of the theory of exit. Another extension which appears accessible at this point is a theory of entry deterrence with multiple incumbents. 
In Section 2 we present the basic model. Post-entry price-setting subgames are examined in Section 3. Section 4 uses the analysis of Section 3 to construct the potential entrant's capacity best-response function for different cost configurations. Then Section 5 examines the incumbent's capacity choice and the qualitative nature of the resulting equilibria. Section 6 concludes.

\section{The Model}

Consider a market for a homogeneous good in which two firms, an incumbent (firm 1) and an entrant (firm 2), sequentially set capacities $k_{i}(i=1,2)$, after which they simultaneously choose prices $p_{i}(i=1,2)$. At the capacity-setting stage, firms incur a lump-sum fixed set-up cost, F, that can be avoided only if zero capacity is installed. In addition, there is a constant per unit cost of capacity, $r$. Hence, the two firms have an identical cost of capacity function, defined as:

$$
\rho\left(k_{i}\right)=\left\{\begin{array}{l}
F+r k_{i} \text { if } k_{i}>0 \\
0 \quad \text { if } k_{i}=0
\end{array}, i=1,2 .\right.
$$

In the final price-setting stage, firm $i$ incurs a constant unit cost of production up to the capacity limit $k_{\mathrm{i}}$. We denote this cost by $c_{\mathrm{i}}$. Thus, if firm i's realized sales at the price-setting stage are $\mathrm{q}_{\mathrm{i}}$ $\leq k_{i}$, its variable cost of production is equal to

$$
c_{i}\left(q_{i}\right)=c_{i} q_{i} \quad \text { for } q_{i} \leq k_{i}, i=1,2 \text {. }
$$

Output greater than a firm's capacity is assumed to be infinitely costly.

Summing the cost of capacity (1) and the cost of production up to capacity (2) yields the cost structure commonly used in the examination of entry deterrence. (See, for example, Dixit (1980).) We explicitly separate these two costs in order to highlight the distinction between the cost of capacity, which is sunk before the final price-setting stage, and the cost of production, which depends on realized sales at the pricing stage. 
Aggregate market demand is assumed to be of the form

$$
\mathrm{d}(\mathrm{p})=\max (1-\mathrm{p}, 0)
$$

Linear demand permits closed form solutions for the equilibrium in the price-setting subgames. It also provides an important benchmark for gauging the relative importance of the regions of the parameter space $\left\{c_{1}, c_{2}, r, F\right\}$ over which different types of preemptive behavior are observed. The qualitative results of our model would be similar, however, if instead demand were assumed to be concave.

Because sharp capacity constraints limit the amount of output that can be supplied, firms may have to ration customers at the prices they select. Following Levitan and Shubik (1972) and Kreps and Scheinkman (1983), we assume that demand is rationed efficiently. Thus, if $p_{i}<p_{j}$, then firm $i$ sells $\min \left(k_{i}, d\left(p_{i}\right)\right)$ and firm $j$ faces a residual demand equal to $\max \left(0, d\left(p_{j}\right)-\right.$ $\mathrm{k}_{\mathrm{i}}$ ). This means that items are sold first to those consumers having the highest willingness to pay if we assume that total demand is generated by a continuum of agents who purchase at most a single unit of an indivisible good. ${ }^{17}$ When firms set identical prices, we assume that all demand first flows to the low-cost firm and that the high-cost firm serves any residual demand. To break ties when $c_{1}=c_{2}$, we arbitrarily let firm 1 sell its capacity first. ${ }^{18}$

With this rationing rule, and ignoring sunk set-up and capacity costs, the profit to firm $i$ in the price-setting subgame when it sets $p_{i}$ and firm $j$ sets $p_{j}$ is

${ }^{17}$ Alternatively, with elastic individual demand, such a rule would result if there were an efficient resale market among consumers.

${ }^{18}$ Any alternative division of sales when firms choose identical prices (such as making them proportional to capacity) would generate the same equilibrium profits in the pricing subgame, as shown in Deneckere and Kovenock (1989b, Proposition 3). 


$$
\pi_{i}\left(p_{i}, p_{j} l k_{i}, k_{j}\right) \equiv \begin{cases}L_{i}\left(p_{i}\right) \equiv\left(p_{i}-c_{i}\right) \min \left(k_{i}, d\left(p_{i}\right)\right) & \text { if } p_{i}<p_{j} \\ T_{i}\left(p_{i}\right) \equiv\left(p_{i}-c_{i}\right) \min \left(k_{i}, \max \left(0, d\left(p_{i}\right)-r_{h}^{i} k_{j}\right)\right) & \text { if } p_{i}=p_{j} \\ H_{i}\left(p_{i}\right) \equiv\left(p_{i}-c_{i}\right) \min \left(k_{i}, \max \left(0, d\left(p_{i}\right)-k_{j}\right)\right) & \text { if } p_{i}>p_{j}\end{cases}
$$

where $I_{h}^{i}$ is an indicator that takes on the value 1 if $c_{i}>c_{j}$, or $c_{1}=c_{2}$ and $i=2$, and takes on the value 0 if $c_{i}<c_{j}$, or $c_{1}=c_{2}$ and $i=1$.

In the analysis that follows, we rule out strategies in which firms price below their unit production costs. ${ }^{19}$ Let $S_{i}=\left[c_{i}, 1\right]$ denote the pure strategy set of firm $i$, and write $\Sigma_{i}$ for the corresponding set of mixed strategies (the set of cumulative distribution functions $\mathrm{F}_{\mathrm{i}}$ on $\mathrm{S}_{\mathrm{i}}$ ). The profit function $\pi_{\mathrm{i}}$ extends in a natural way to an expected profit function on $\Sigma_{1} \times \Sigma_{2}$. For any quadruple of capacities and costs $\left(k_{1}, k_{2}, c_{1}, c_{2}\right)$, the price-setting subgame is then a normal form game $G\left(k_{1}, k_{2}, c_{1}, c_{2}\right)$, with players $i=1,2$, strategy sets $\Sigma_{\mathrm{i}}$, and expected payoff functions $\pi_{\mathrm{i}}\left(\mathrm{F}_{1}, \mathrm{~F}_{2}\right)$.

In Section 3 we demonstrate that there is a unique Nash equilibrium pair of payoffs in the game $G\left(k_{1}, k_{2}, c_{1}, c_{2}\right)$, denoted by $\pi_{i}^{*}\left(k_{1}, k_{2}, c_{1}, c_{2}\right)$ for $i=1,2$. Since we are interested in the subgame perfect equilibria only, the three-stage game of sequential capacity choice followed by simultaneous price-setting can be reduced to a game of sequential capacity choice with payoffs $\Pi_{i}\left(k_{1}, k_{2} \mid c_{1}, c_{2}, r, F\right)=\pi_{i}^{*}\left(k_{1}, k_{2}, c_{1}, c_{2}\right)-\rho\left(k_{i}\right)$. We call this game $\Gamma\left(c_{1}, c_{2}, r, F\right)$. Throughout the continuation we mostly ignore trivial cases associated with drastic cost advantages by assuming that $c_{i}<\left(1+c_{j}+r\right) / 2, i=1,2, j \neq i$.

Let the inverse demand function corresponding to (3) be denoted by $P(q)=\max \{0,1-q\}$. In analyzing the game $\Gamma$, we often need to refer to best-response functions in the quantity-setting game with inverse demand function $P(q)$ and various cost functions. Let $Q_{i}^{c}\left(k_{j}\right)=\arg \max _{q}$ $\left\{\left[P\left(q+k_{j}\right)-c_{i}\right] q\right\}, Q_{i}^{r}\left(k_{j}\right)=\arg \max _{q}\left\{\left[P\left(q+k_{j}\right)-c_{i}-r\right] q\right\}$ and $Q_{i}^{F}\left(k_{j}\right)=\arg \max _{q}\left[P\left(q+k_{j}\right) q-c_{i} q-\right.$

${ }^{19}$ We therefore rule out any weakly dominated strategy that is not the limit of a sequence of undominated strategies. 
$\rho(q)]$ be the best-response functions corresponding to the cost functions $c_{i} q,\left(c_{i}+r\right) q$, and $c_{i} q+$ $\rho(q)$, respectively. More precisely: ${ }^{20}$

$$
\begin{aligned}
& Q_{i}^{c}\left(k_{j}\right)=\max \left\{0, \frac{1}{2}\left(1-k_{j}-c_{i}\right)\right\} \\
& Q_{i}^{r}\left(k_{j}\right)=\max \left\{0, \frac{1}{2}\left(1-k_{j}-c_{i}-r\right)\right\} \\
& Q_{i}^{F}\left(k_{j}\right)= \begin{cases}\frac{1}{2}\left(1-k_{j}-c_{i}-r\right) & \text { if } k_{j}<1-c_{i}-r-2 \sqrt{F} \\
0 & \text { otherwise. }\end{cases}
\end{aligned}
$$

Let $\mathrm{k}^{\mathrm{C}}(\alpha, \beta) \equiv\left(\mathrm{k}_{1}^{\mathrm{C}}(\alpha, \beta), \mathrm{k}_{2}^{\mathrm{C}}(\alpha, \beta)\right)$ be the intersection of $\mathrm{Q}_{1}^{\alpha}$ and $\mathrm{Q}_{2}^{\beta}$, for $\alpha, \beta \in\{c, r\}$. Thus, for example, $k_{i}^{C}(r, r)=\left(1-2 c_{i}+c_{j}-r\right) / 3$ are the Cournot capacities when firms have unit costs $c_{i}+r$ $(i=1,2)$. Analogously, let $k^{\mathrm{s}}(\alpha, \beta) \equiv\left(\mathrm{k}_{1}^{\mathrm{s}}(\alpha, \beta), \mathrm{k}_{2}^{\mathrm{s}}(\alpha, \beta)\right)$ be the Stackelberg equilibrium point when the leader (firm 1) has cost structure $\alpha$ and the follower has best-response function $Q_{2}^{\beta}$, for $\alpha, \beta \in$ $\{c, r, F\}$. For example, $k_{1}^{s}(r, r)=\left(1-2 c_{1}+c_{2}-r\right) / 2$, and $k_{2}^{s}(r, r)=\max \left(0,\left(1-3 c_{2}+2 c_{1}-r\right) / 4\right)$.

\section{The Price-Setting Subgames}

We now derive Nash equilibrium profits in the price-setting subgame $G\left(k_{1}, k_{2}, c_{1}, c_{2}\right)$. For a more complete treatment see Deneckere and Kovenock (1989a, b), which shows that, except in cases where the high-cost firm makes zero profits, equilibrium strategies are uniquely determined.

To describe equilibrium profits note that, for some ranges of costs and capacities, equilibrium exists in pure strategies, while in other regions, equilibrium requires nondegenerate mixed strategies. Figure 3 illustrates these respective regions for the case where $c_{1}<c_{2}$. If both

${ }^{20}$ Note that we have assumed that the best-response function $Q_{i}^{F}$ is left continuous; this ensures that in a Stackelberg game the leader can always attain the supremum of its profits, so that an equilibrium exists. 
firms' capacities are sufficiently small, so that $k_{i} \leq Q_{i}^{c}\left(k_{j}\right)$ for each $i$, then there is a unique Nash equilibrium in which both firms set the price $P\left(k_{1}+k_{2}\right)=1-k_{1}-k_{2}$ and produce at full capacity. Respective profits are given by $\pi_{i}^{*}=\left(1-k_{1}-k_{2}-c_{i}\right) k_{i}, i=1,2$. This region is labeled region $A$ in Figure 3.

In region $B=B_{1} \cup B_{2} \cup B_{3} \cup B_{4}$, the equilibrium involves nondegenerate mixed strategies. The derivation of equilibrium expected profits follows a simple procedure. Note first that firm i makes at least as much profit when it is the low-priced firm as when it is high-priced. Hence, firm $\mathrm{i}$ can guarantee itself a minimax profit of $\mathrm{H}_{\mathrm{i}}^{*} \equiv \max _{\mathbf{p}} \mathrm{H}_{\mathrm{i}}(\mathrm{p})=\left[\max \left(1-\mathrm{k}_{\mathrm{i}}-\mathrm{k}_{\mathrm{j}}\right.\right.$, $\left.\left.\frac{1-k_{j}+c_{i}}{2}, c_{i}\right)-c_{i}\right] \cdot \min \left[k_{i}, \frac{1-k_{j}-c_{i}}{2}\right]$ by charging the price which maximizes its profit under the assumption that it is the high-priced firm, $p_{i}^{H} \equiv \underset{p}{\operatorname{argmax}} H_{i}(p)=\max \left(1-k_{i}-k_{j}, \frac{1-k_{j}+c_{i}}{2}, c_{i}\right) \cdot{ }^{21}$ This implies that, in equilibrium, firm i never charges a price at which it receives a profit less than $H_{i}^{*}$ when it is the low-priced firm. More specifically, firm i never charges a price less than $\mathrm{p}_{\mathrm{i}} \equiv \min \left\{\mathrm{p}: \mathrm{L}_{\mathrm{i}}(\mathrm{p})=\mathrm{H}_{\mathrm{i}}^{*}\right\}$. For our linear example,

$$
\mathrm{p}_{i}= \begin{cases}1-\mathrm{k}_{\mathrm{i}}-\mathrm{k}_{\mathrm{j}} & \text { if } \mathrm{k}_{\mathrm{j}} \leq 1-\mathrm{c}_{\mathrm{i}}-2 \mathrm{k}_{\mathrm{i}} \\ \max \left\{\frac{1}{\mathrm{k}_{\mathrm{i}}}\left(\frac{1-\mathrm{k}_{\mathrm{j}}-\mathrm{c}_{\mathrm{i}}}{2}\right)^{2}+\mathrm{c}_{\mathrm{i}}, \frac{1+\mathrm{c}_{\mathrm{i}}}{2}-\frac{1}{2}\left[\mathrm{k}_{\mathrm{j}}\left(2\left(1-\mathrm{c}_{\mathrm{i}}\right)-\mathrm{k}_{\mathrm{j}}\right)\right]^{1 / 2}\right\} & \text { if } 1-c_{\mathrm{i}}-2 \mathrm{k}_{\mathrm{i}} \leq \mathrm{k}_{\mathrm{j}} \leq 1-c_{\mathrm{i}} \\ \mathrm{c}_{\mathrm{i}} & \text { if } \mathrm{k}_{\mathrm{j}} \geq 1-\mathrm{c}_{\mathrm{i}} .\end{cases}
$$

Any price below $p_{i}$ is payoff-dominated by charging $p_{i}^{H}$.

To distinguish between the two firms in region $B$, suppose that $p_{j} \leq p_{i}$. Then firm $j$ knows that it is never undercut at prices below $p_{i}$. Since $L_{j}(p)$ is increasing on the interval below $\mathrm{p}_{\mathrm{i}}$, neither firm ever charges a price below $\mathrm{p}_{\mathrm{i}}$.

One can easily show that in this region, when $\mathrm{p}_{j} \leq \mathrm{p}_{\mathrm{i}}$, we have $\mathrm{p}_{i}>\mathrm{P}\left(\mathrm{k}_{1}+\mathrm{k}_{2}\right)=$ $\max \left(0,1-k_{1}-k_{2}\right)$. Let $\bar{s}_{k}$ be the upper bound of the support of firm $k^{\prime}$ 's equilibrium price

${ }^{21}{ }_{\text {If }} k_{j} \geq 1-c_{i}$, we use the convention that $p_{i}^{H}=c_{i}$. 
distribution, $\mathrm{F}_{\mathrm{k}}^{*}$, and define $\overline{\mathrm{s}} \equiv \max \left\{\overline{\mathrm{s}}_{1}, \overline{\mathrm{s}}_{2}\right\}$. Clearly, one has $\overline{\mathrm{s}}>\mathrm{P}\left(\mathrm{k}_{1}+\mathrm{k}_{2}\right)$. Hence, at least one firm must sell strictly less than its capacity when it sets its price equal to $\bar{s}$. Furthermore, at most one firm can have a mass point in its equilibrium price distribution at $\overline{\mathrm{s}}$. (If both had a mass point, each firm could increase expected sales discretely by moving its mass point slightly below $\bar{s}$.) This implies that for some firm $k, \bar{s}$ is contained in the support of $F_{k}^{*}$ and firm $k$ 's equilibrium profit is $\mathrm{H}_{\mathbf{k}}(\mathrm{s})$. For this firm to be playing a best response to its rival's strategy, we must have $\overline{\mathrm{s}}=\mathrm{p}_{\mathrm{k}}^{\mathrm{H}}$. Hence, firm $\mathrm{k}$ 's equilibrium profit equals $\mathrm{H}_{\mathrm{k}^{*}}^{*}$. If $\mathrm{p}_{\mathrm{j}}<\mathrm{p}_{\mathrm{i}}$, firm $\mathrm{j}$ can always assure itself an equilibrium profit strictly greater than $H_{j}^{*}$, since $L_{j}\left(p_{i}\right)>L_{j}\left(p_{j}\right)=H_{j}^{*}$. Therefore, firm i earns $H_{i}^{*}$.

Let $\underline{s}_{j}$ be the lower bound of the support of firm j's equilibrium price distribution, and suppose that $\underline{s}_{j}>\underline{p}_{i}$. Then firm $i$ could set a price $p$ between $\underline{p}_{i}$ and $\underline{s}_{j}$ and earn $L_{i}(p)>L_{i}\left(p_{i}\right)=H_{i}^{*}$, a contradiction. Hence, $\underline{s}_{j}=p_{i}$ and firm j's equilibrium profit is $L_{j}\left(p_{i}\right)$.

Following this procedure, to determine equilibrium profits in region $\mathrm{B}$, one needs only to calculate $\mathrm{p} \equiv \max \left\{\underline{p}_{1}, \underline{p}_{2}\right\}$. Equilibrium profits are then $L_{i}(p), i=1,2$. An explicit functional form for profit when demand is described by (3) appears in Deneckere and Kovenock (1989a) and is replicated in the Appendix for convenience. Under our assumptions, region B can be partitioned into two connected subregions in which $\underline{p}_{1} \geq \underline{p}_{2}$ and $\underline{p}_{2}>\underline{p}_{1}$. The common boundary of these two regions is comprised of capacity pairs $k_{1}>0$ and $k_{2}>0$ for which $p_{1}=p_{2}$ and is denoted by $\theta_{2}\left(k_{1}\right)$. In our linear example this boundary consists of all $\left(k_{1}, k_{2}\right)$ pairs that solve $k_{1}\left(1-k_{1}-c_{2}\right)^{2}+4 k_{1} k_{2}\left(c_{2}-c_{1}\right)-k_{2}\left(1-k_{2}-c_{1}\right)^{2}=0$, with $k_{1}$ ranging between $k_{1}^{C}(c, c)$ and $k_{1}=$ $\mathrm{d}\left(\mathrm{c}_{2}\right)$. For $\mathrm{k}_{1} \geq \mathrm{d}\left(\mathrm{c}_{2}\right), \mathrm{p}_{2}\left(\mathrm{k}_{1}, \mathrm{k}_{2}, \mathrm{c}_{1}, \mathrm{c}_{2}\right)$ equals $\mathrm{c}_{2}$, and the boundary $\theta_{2}\left(\mathrm{k}_{1}\right)$ coincides with the horizontal line $k_{2}=\varphi\left(c_{1}, c_{2}\right) \equiv 1-c_{1}-2\left[\left(1-c_{2}\right)\left(c_{2}-c_{1}\right)\right]^{1 / 2}$. Capacity pairs $\left(k_{1}, k_{2}\right)$ with $k_{1} \geq$ $\mathrm{d}\left(\mathrm{c}_{2}\right)$ and $\mathrm{k}_{2}<\varphi\left(\mathrm{c}_{1}, \mathrm{c}_{2}\right)$ remain in region $\mathrm{B}$; the price-setting equilibrium requires nondegenerate mixed strategies. Capacity pairs in the set $\left\{\left(k_{1}, k_{2}\right): k_{1} \geq d\left(c_{2}\right)\right.$ and $\left.k_{2} \geq \varphi\left(c_{1}, c_{2}\right)\right\}$ lie in the classical Bertrand region (region $\mathrm{C}$ in Figure 3); equilibrium requires that the low-cost firm price the high-cost firm out of the market, so that $\pi_{2}^{*}=0$. Given our assumption that no firm ever prices below its unit cost, firm 1 earns $\pi_{1}^{*}=\max _{p \leq c_{2}}\left(p-c_{1}\right) \min \left(k_{1}, 1-p\right)$. 
The curves $k_{i}=\Psi_{i}\left(k_{j}\right)$ are the loci of points $\left(k_{1}, k_{2}\right)$ for which firm $i$ is exactly capacity constrained when it charges $\mathrm{p}_{\mathrm{i}} ;$ i.e., $\mathrm{d}\left(\mathrm{p}_{\mathrm{i}}\right)=\mathrm{k}_{\mathrm{i}}$. For the demand function $(3), \Psi_{\mathrm{i}}\left(\mathrm{k}_{\mathrm{j}}\right)=$ $\frac{1-c_{i}}{2}+\frac{1}{2}\left\{k_{j}\left[2\left(1-c_{i}\right)-k_{j}\right]\right\}^{1 / 2}$ for $0 \leq k_{j} \leq 1-c_{i}$ and $\Psi_{i}\left(k_{j}\right)=1-c_{i}$ for $k_{j} \geq 1-c_{i}$. Using these curves, we may further subdivide region $B$ into four different regions. In region $B_{1}$, $\mathrm{k}_{2}>d\left(\underline{p}_{2}\right)$ and $\underline{p}_{2}>\underline{p}_{1}$. Hence, equilibrium profits are given by $\pi_{2}^{*}=L_{2}\left(\underline{p}_{2}\right)=\left(\underline{p}_{2}-c_{2}\right) d\left(\underline{p}_{2}\right)$ and $\pi_{1}^{*}=L_{1}\left(\underline{p}_{2}\right)=\left(\underline{p}_{2}-c_{1}\right) k_{1}$. In region $B_{2}, k_{2}<d\left(\underline{p}_{2}\right)$ and $\underline{p}_{2}>\underline{p}_{1}$, so that $\pi_{2}^{*}=\left(\underline{p}_{2}-c_{2}\right) k_{2}$ and $\pi_{1}^{*}=\left(\underline{p}_{2}-c_{1}\right) k_{1}$. In region $B_{3}, k_{1}<d\left(p_{1}\right)$ and $p_{1}>\underline{p}_{2}$, and hence $\pi_{2}^{*}=\left(\underline{p}_{1}-c_{2}\right) k_{2}$ and $\pi_{1}^{*}=\left(\underline{p}_{1}-c_{1}\right) k_{1}$. Finally, in region $B_{4}, p_{1}>p_{2}$ but $d\left(p_{1}\right)<k_{1}$, so that $\pi_{2}^{*}=\left(p_{1}-c_{2}\right) k_{2}$ and $\pi_{1}^{*}=\left(\mathrm{p}_{1}-\mathrm{c}_{1}\right) \mathrm{d}\left(\mathrm{p}_{1}\right)$.

The analysis of the case where $c_{2}<c_{1}$ is entirely analogous and is illustrated in Figure 4. In region $A, k_{i} \leq Q_{i}^{c}\left(k_{j}\right)$ for $i=1$ and $i=2$, so that there is a pure strategy equilibrium in which both firms charge $P\left(k_{1}+k_{2}\right)$ and produce at full capacity. The curve $\theta_{1}\left(k_{2}\right)$ again divides the regions where $\underline{p}_{1}>\underline{p}_{2}$ and $\underline{p}_{2}>\underline{p}_{1} \cdot{ }^{22}$ Equilibrium profits are $L_{i}\left(p_{1}\right)$ over the region where $\underline{p}_{1}>\underline{p}_{2}$ and $L_{i}\left(p_{2}\right)$ over the region where $\underline{p}_{2}>\underline{p}_{1}$. In region $C$, firm 1 is forced to exit the market, so that $\pi_{1}^{*}=0$ and $\pi_{2}^{*}=\max _{p \leq c_{1}}\left(p-c_{2}\right) \min \left(k_{2}, d(p)\right)$.

We may summarize the behavior outside the pure strategy region $A$ as follows: When $\underline{p}_{1}>\underline{p}_{2}$, firm 1 prices passively by providing a stochastic price umbrella for firm $2 .{ }^{23}$ Consequently, here we have $\pi_{1}^{*}=H_{1}^{*}$ and $\pi_{2}^{*}=L_{2}\left(\underline{p}_{1}\right)$. When $c_{1}=c_{2}$, the inequality $\underline{p}_{1}>\underline{p}_{2}$ holds if and only if $k_{1}>k_{2}$, so that large firms price passively and small firms price aggressively. When $c_{1}>c_{2}$, the region where $\underline{p}_{1}>\underline{p}_{2}$ strictly includes the region where $k_{1}>k_{2}$; when $c_{1}<c_{2}$, the opposite is true. Thus, as is emphasized in Deneckere and Kovenock (1992), high costs induce more passive pricing behavior.

${ }^{22}$ For $\mathrm{k}_{2}$ ranging between $\mathrm{k}_{2}^{\mathrm{C}}(\mathrm{c}, \mathrm{c})$ and $\mathrm{d}\left(\mathrm{c}_{1}\right)$, this curve is defined by the implicit equation $k_{2}\left(1-k_{2}-c_{1}\right)^{2}+4 k_{1} k_{2}\left(c_{1}-c_{2}\right)-k_{1}\left(1-k_{1}-c_{2}\right)^{2}=0$. For $k_{2} \geq d\left(c_{1}\right), \theta_{1}\left(k_{2}\right)=\varphi\left(c_{2}, c_{1}\right)=$ $1-c_{2}-2\left[\left(1-c_{1}\right)\left(c_{1}-c_{2}\right)\right]^{1 / 2}$.

${ }^{23}$ We use the term aggressive pricing to indicate that a firm undercuts its rival with sufficiently high probability so as to keep that rival at its minimax profit level. The rival, which allows itself to be undercut sufficiently often, is then said to price passively. 


\section{Capacity Best-Response Functions}

Before proceeding with the derivation of the follower's best-response function in the game $\Gamma\left(c_{1}, c_{2}, r, F\right)$, we would like to provide some intuition for why and how this best-response function differs from the standard quantity best-response function in the Cournot and Stackelberg models. The distinction between our capacity best-response and the standard quantity best response emanates from the following observation: In quantity-setting models a quantity placed on the market is a commitment to drive price down to the level that clears all quantity from the market. In the three-stage game of sequential capacity choice followed by simultaneous pricesetting, capacity is not a commitment to drive price down to the capacity_clearing level.

This fact has two major implications. First, when firms' costs are not too dissimilar and for capacities outside of the region under the lower envelope of the Cournot best-response functions $Q_{i}^{c}\left(k_{j}\right)$, the larger firm acts relatively passively in pricing. ${ }^{24}$ This provides an incentive for a follower to set a capacity above the quantity best-response function when the leader's capacity is sufficiently large. In this range, the gain from the follower's expansion of capacity beyond the level corresponding to the quantity best response is only partially offset by a (stochastic) price reduction.

The second major implication is that firms whose efficiency considerably exceeds that of their rivals act more aggressively in setting capacity than they would in quantity-setting games. Efficient followers need not take their rival's capacity as a commitment to sell. Instead, they may decide to increase their own capacity to accommodate all of the demand at their rival's unit cost of production and proceed to price the rival completely out of the market. Hence, Bertrand behavior may displace Cournot behavior.

The potential for this type of aggressive response has an important effect on the behavior of a leader with high unit production costs. Such a firm will restrict its capacity in order to

${ }^{24}$ As shown in Section 3, this statement is literally true when the larger firm is equally or less efficient than its opponent. When the large firm is more efficient (e.g., $\left.c_{1}<c_{2}\right)$, the statement also holds true in the region where $p_{1}>p_{2}$. This suffices for our purposes, as firm 2's quantity best-response function is entirely contained in this region whenever $\left(k_{1}, k_{2}\right) \notin A$. 
render it optimal for the more efficient firm to restrict capacity and price passively rather than to expand capacity and price aggressively.

In the analysis that follows, we characterize the parameter values that delineate these two types of behavior. From the equilibrium profits $\Pi_{i}\left(k_{1}, k_{2} \mid c_{1}, c_{2}, r, F\right)$ of the price-setting subgames, we can calculate the optimal capacity choice of the follower in the second stage of our three-stage game:

$$
\mathrm{R}\left(\mathrm{k}_{1}\right) \equiv \underset{\mathrm{k}_{2}}{\operatorname{argmax}} \Pi_{2}\left(\mathrm{k}_{1}, \mathrm{k}_{2} \mid \mathrm{c}_{1}, \mathrm{c}_{2}, \mathrm{r}, \mathrm{F}\right) \text {. }
$$

Define $\mathrm{R}^{0}\left(\mathrm{k}_{1}\right)$ to be the follower's capacity best-response function when the fixed set-up cost is equal to zero:

$$
\mathrm{R}^{0}\left(\mathrm{k}_{1}\right)=\underset{\mathrm{k}_{2}}{\operatorname{argmax}} \Pi_{2}\left(\mathrm{k}_{1}, \mathrm{k}_{2} \mid \mathrm{c}_{1}, \mathrm{c}_{2}, \mathrm{r}, 0\right)
$$

Since the follower's profits are nonincreasing in $k_{1}$, and since a fixed set-up cost does not affect the best-response capacity unless profits become nonpositive, $R\left(k_{1}\right)$ coincides with $R^{0}\left(k_{1}\right)$ below a critical value of the leader's capacity: 25

$$
R\left(k_{1}\right)= \begin{cases}R^{0}\left(k_{1}\right) & \text { if } k_{1}<k^{m} \\ 0 & \text { if } k_{1} \geq k^{m}\end{cases}
$$

The critical value $\mathrm{k}^{\mathrm{m}}$ is defined by ${ }^{26}$

$$
\mathrm{k}^{\mathrm{m}}\left(\mathrm{c}_{1}, \mathrm{c}_{2}, \mathrm{r}, \mathrm{F}\right)=\max \left\{\mathrm{k}_{1}: \Pi_{2}\left(\mathrm{k}_{1}, \mathrm{R}^{0}\left(\mathrm{k}_{1}\right) \mid \mathrm{c}_{1}, \mathrm{c}_{2}, \mathrm{r}, 0\right) \geq F\right\}
$$

${ }^{25}$ Following Dixit, we assume that whenever the follower is indifferent between entering and staying out of the market, no entry occurs. More generally, whenever the follower's bestresponse correspondence is multiple valued we assume that the follower takes the action that maximizes the leader's profit. This ensures that the leader's first-stage profit function $\Pi_{1}\left(k_{1}, R\left(k_{1}\right) \mid c_{1}, c_{2}, r, F\right)$ is upper semicontinuous, so that an equilibrium always exists.

${ }^{26}$ We adopt the following conventions in the definition of $\mathrm{k}^{\mathrm{m}}$ : if the set over which $\mathrm{k}_{1}$ is being maximized is empty, then $k^{m}\left(c_{1}, c_{2}, r, F\right)=0$. If the set is equal to $R_{+}$, then $k^{m}\left(c_{1}, c_{2}, r, F\right)=\infty$. Note that the former case occurs when $F$ is sufficiently large, and the latter case occurs when $c_{2}$ is not too much larger than $c_{1}$ and $F$ is sufficiently small. 
Because of this simple relationship between $R\left(k_{1}\right)$ and $R^{0}\left(k_{1}\right)$, we will first assume (in order to simplify our presentation) that $F=0$ and study how $R^{0}\left(k_{1}\right)$ depends on the remaining parameters $c_{1}, c_{2}$, and $r$. Figure 5 illustrates the different cases that may arise.

Proposition 1: Suppose $r \geq\left(1-2 c_{2}+c_{1}\right) / 2$. Then $R^{0}\left(k_{1}\right)=Q_{2}^{r}\left(k_{1}\right)$.

When $r \geq\left(1-2 c_{2}+c_{1}\right) / 2, Q_{2}^{r}\left(k_{1}\right)$ lies entirely in region $A$. The cost of capacity is so high that it is never optimal for firm 2 to select a capacity $k_{2}$ such that $\left(k_{1}, k_{2}\right)$ lies outside of region $A$, even if this firm is cost advantaged. Since all capacity pairs in region A lead to price-setting equilibria in which price clears all capacity from the market, $R^{0}\left(k_{1}\right)$ coincides with $Q_{2}^{T}\left(k_{1}\right)$. Figure 5a shows an example of this type of best response, where $c_{1}=c_{2}=0$ and $r=.5$.

In the next proposition, the inequalities $r<\left(1-2 c_{2}+c_{1}\right) / 2$ and $c_{2} \geq c_{1}-\Delta\left(c_{1}, r\right)$ hold, for some function $\Delta\left(c_{1}, r\right)$ satisfying $\Delta\left(c_{1}, r\right)>r$. The capacity cost is then small enough that $Q_{2}^{r}\left(k_{1}\right)$ lies outside of region $A$ for $k_{1}>k_{1}^{C}(c, r)$, but firm 2's cost advantage (if any) is small enough that it is never optimal to drive firm 1 out of the market. As in Proposition $1, \mathrm{R}^{0}\left(\mathrm{k}_{1}\right)$ coincides with $Q_{2}^{r}\left(k_{1}\right)$ for $k_{1} \leq k_{1}^{C}(c, r)$. However, for $k_{1}>k_{1}^{C}(c, r), R^{0}\left(k_{1}\right)$ lies entirely above $Q_{2}^{r}\left(k_{1}\right)$. This is most evident for $k_{1}>d\left(c_{2}\right)$, where $Q_{2}^{T}\left(k_{1}\right)=0$ but $R^{0}\left(k_{1}\right)>0$. Recall from Section 3 that $\pi_{2}^{*}\left(k_{1}, k_{2}, c_{1}, c_{2}\right)>0$ for $k_{2}>0$ if $c_{2}<c_{1}$ and for $0<k_{2}<\varphi\left(c_{1}, c_{2}\right)$ if $c_{1} \leq c_{2}$. The condition $r<\left(1-2 c_{2}+c_{1}\right) / 2$ then insures that there exists $\bar{k}_{2}>0$ such that $\Pi_{2}=\pi_{2}^{*}-\mathrm{rk}_{2}>0$ for $\mathrm{k}_{2} \in$ $\left(0, \bar{k}_{2}\right)$, regardless of the value of $k_{1}$. As in Gelman and Salop (1983), by choosing a sufficiently small but positive capacity, the follower can guarantee that the leader does not find it profitable to drive the follower out of the market in the price-setting subgame. The leader then prefers to provide a stochastic price umbrella for its relatively small rival, rather than to lower its price sufficiently far so as to make it impossible for the rival to obtain any profitable sales.

To be more specific, define the judo capacity of firm 2 by $\lambda_{2}\left(c_{1}, c_{2}, r\right) \equiv \arg \max _{k_{2}}$ $\left\{\Pi_{2}\left(\mathrm{~d}\left(\mathrm{c}_{2}\right), \mathrm{k}_{2}\right)\right\}$. Note that $\lambda_{2}$ provides firm 2 with the highest profit attainable in region $\mathrm{B}_{4}$ since $\underline{p}_{1}$ (and hence, $\Pi_{2}\left(k_{1}, k_{2}\right)$ ) is independent of $k_{1}$ in $B_{4}$. Let $k^{J}\left(c_{1}, c_{2}, r\right) \equiv \inf \left\{k_{1}\right.$ : 
$\left.\max _{\left\{k_{2}:\left(k_{1}, k_{2}\right) \in B_{3}\right\}} \Pi_{2}\left(k_{1}, k_{2}\right) \leq \Pi_{2}\left(d\left(c_{2}\right), \lambda_{2}\right)\right\}$. Then for $k_{1}<k^{J}$ firm 2 's optimal response lies in region $B_{3}$ and for $k_{1} \geq k^{J}$ firm 2's optimal response lies in region $B_{4}$. Finally, define $\Delta\left(c_{1}, r\right) \equiv c_{1}$ $-\min \left\{c_{2}: \Pi_{2}\left(k^{J}, \lambda_{2}, c_{1}, c_{2}\right) \geq d\left(c_{1}\right)\left(c_{1}-c_{2}-r\right)\right\}$. We can now state

Proposition 2: Suppose $r<\left(1-2 c_{2}+c_{1}\right) / 2$ and $c_{2} \geq c_{1}-\Delta\left(c_{1}, r\right)$. Then the capacity bestresponse function is given by

$$
\mathrm{R}^{0}\left(\mathrm{k}_{1}\right)= \begin{cases}\mathrm{Q}_{2}^{\mathrm{r}}\left(\mathrm{k}_{1}\right) & \text { if } 0 \leq \mathrm{k}_{1} \leq \mathrm{k}_{1}^{\mathrm{C}}(\mathrm{c}, \mathrm{r}) \\ \left\{2\left(1-\mathrm{c}_{1}\right)-\left[\left(1-\mathrm{c}_{1}\right)^{2}-12 \mathrm{k}_{1}\left(\mathrm{c}_{1}-\mathrm{c}_{2}-\mathrm{r}\right)\right]^{1 / 2}\right\} / 3 & \text { if } \mathrm{k}_{1}^{\mathrm{C}}(\mathrm{c}, \mathrm{r})<\mathrm{k}_{1}<\mathrm{k}^{\mathrm{J}} \\ \lambda_{2}\left(\mathrm{c}_{1}, \mathrm{c}_{2}, \mathrm{r}\right) & \text { if } \mathrm{k}_{1} \geq \mathrm{k}^{\mathrm{J}} .\end{cases}
$$

In Proposition 2 the middle branch of $R^{0}\left(k_{1}\right)$ lies in region $B_{3}$. If $c_{1}<c_{2}+r, R^{0}\left(k_{1}\right)$ has a negative slope over this range (see Figure $5 b$ ), while if $c_{1}>c_{2}+r$, it has a positive slope (see Figure 5c). Either way, a Proposition 2 best-response function jumps down when $\mathrm{k}_{1}=\mathrm{k}^{\mathrm{J}}\left(\mathrm{c}_{1}, \mathrm{c}_{2}, \mathrm{r}\right)$. At the point $\mathrm{k}_{1}=\mathrm{k}^{\mathrm{J}}$, firm 2's maximum profit from responding with a capacity that leaves firm 1 capacity constrained at $\underline{p}_{1}$ equals its profit from setting $k_{2}=\lambda_{2}\left(c_{1}, c_{2}, r\right)$, a capacity sufficiently small that firm 1 is not capacity constrained at $\underline{\underline{p}}_{1}$. For $k_{1} \geq k^{J}$ firm 2 responds optimally by selecting its judo capacity $\lambda_{2}$.

Proposition 3: Suppose $\mathrm{r}<\left(1-2 \mathrm{c}_{2}+\mathrm{c}_{1}\right) / 2$ and $\mathrm{c}_{2}<\mathrm{c}_{1}-\Delta\left(\mathrm{c}_{1}, \mathrm{r}\right)$. Define $\mathrm{k}^{\mathrm{u}}\left(\mathrm{c}_{1}, \mathrm{c}_{2}, \mathrm{r}\right)=$ $\inf \left\{k_{1}: d\left(c_{1}\right)\left(c_{1}-c_{2}-r\right) \geq \underset{\left\{k_{2}:\left(k_{1}, k_{2}\right) \in A \cup B_{3} \cup B_{4}\right\}}{\max } \Pi_{2}\left(k_{1}, k_{2}\right)\right\}$.

Then $R^{0}\left(k_{1}\right)= \begin{cases}Q_{2}^{r}\left(k_{1}\right) & \text { if } k_{1} \in\left[0, \min \left(k_{1}^{C}(c, r), k^{u}\right)\right] \\ \left\{2\left(1-c_{1}\right)-\left[\left(1-c_{1}\right)^{2}-12 k_{1}\left(c_{1}-c_{2}-r\right)\right]^{1 / 2}\right\} / 3 & \text { if } k_{1} \in\left(\min \left(k_{1}^{C}(c, r), k^{u}\right), k^{u}\right] \\ d\left(c_{1}\right) & \text { if } k_{1}>k^{u} .\end{cases}$ 
In Proposition 3, the follower's cost advantage is then sufficiently large and the cost of capacity sufficiently low that driving the leader out of the market in the price-setting subgame is optimal whenever $\mathrm{k}_{1}$ exceeds some critical level $\mathrm{k}^{\mathrm{u}}$. Note that under the assumptions of Proposition $3 \mathrm{k}^{\mathrm{u}}$ always exists and $\mathrm{k}^{\mathrm{u}}<\mathrm{k}^{\mathrm{J}}$. For $\mathrm{k}_{1} \leq \mathrm{k}^{\mathrm{u}}, \mathrm{R}^{0}\left(\mathrm{k}_{1}\right)$ coincides with the Proposition 2 best-response function, which is given by equation (6). For $k_{1}>k^{u}$, the follower sets a capacity just large enough to serve the market at a price equal to the leader's unit cost of production, $R^{0}\left(k_{1}\right)=d\left(c_{1}\right)$. Note that $\mathrm{k}^{\mathrm{u}}$ may be greater than or less than $\mathrm{k}_{1}^{\mathrm{C}}(\mathrm{c}, \mathrm{r})$; that is, the upward jump in $\mathrm{R}^{0}\left(\mathrm{k}_{1}\right)$ may occur in region $A$ or region $B_{3}$. The boundary of cost parameter sets distinguishing these two possibilities is given by $c_{2}=\left(5 c_{1}-4 r-1\right) / 4 .^{27}$ Figure $5 d$ illustrates $R^{0}\left(k_{1}\right)$ when the jump point occurs in region $B_{3}$ and Figure 5e depicts the situation when it occurs in region $A$.

As noted earlier, a fixed set-up cost alters the capacity best-response function only when it causes the follower's profits to be nonpositive. The follower opts for staying out of the market whenever the leader's capacity exceeds some critical capacity level $\mathrm{k}^{\mathrm{m}}$, whose value depends on which of the conditions of Propositions 1-3 hold. Under the conditions of Proposition 1 we have

Proposition 4: Suppose $r \geq\left(1-2 c_{2}+c_{1}\right) / 2$. Then

$$
R\left(k_{1}\right)= \begin{cases}R^{0}\left(k_{1}\right) & \text { if } k_{1}<k^{m} \\ 0 & \text { if } k_{1} \geq k^{m}\end{cases}
$$

where $k^{m}=1-c_{2}-r-2 \sqrt{F}$.

${ }^{27}$ For $c_{2} \leq\left(5 c_{1}-4 r-1\right) / 4, k^{u}=1-c_{2}-r-2\left[\left(1-c_{1}\right)\left(c_{1}-c_{2}-r\right)\right]^{1 / 2}$ and for $c_{2}>\left(5 c_{1}-4 r-1\right) / 4$ $\mathrm{k}^{\mathrm{u}}=\left(1-\mathrm{c}_{1}\right)^{2} /\left[16\left(\mathrm{c}_{1}-\mathrm{c}_{2}-\mathrm{r}\right)\right]$. 
Observe that in this case $R\left(k_{1}\right)=Q_{2}^{F}\left(k_{1}\right)$, so that the outcome of our three-stage game then coincides with the Stackelberg outcome $k^{s}(F, F)$. Under conditions parallel to Proposition 2, we have

Proposition 5: Suppose $r<\left(1-2 c_{2}+c_{1}\right) / 2$ and $c_{2} \geq c_{1}-\Delta\left(c_{1}, r\right)$. Then

$$
R\left(k_{1}\right)= \begin{cases}R^{0}\left(k_{1}\right) & \text { if } k_{1}<k^{m} \\ 0 & \text { if } k_{1} \geq k^{m}\end{cases}
$$

where $\mathrm{k}^{\mathrm{m}}$ is given $\mathrm{by}^{28}$

$$
k^{m}= \begin{cases}\infty & \text { if } \Pi_{2}\left(k^{J}, \lambda_{2} \mid c_{1}, c_{2}, r, 0\right)>F \\ \eta\left(c_{1}, c_{2}, r, F\right) & \text { if } \Pi_{2}\left(k^{J}, \lambda_{2} \mid c_{1}, c_{2}, r, 0\right) \leq F<\Pi_{2}\left(k^{C}(c, r) \mid c_{1}, c_{2}, r, 0\right) \\ 1-c_{2}-r-2 \sqrt{F} & \text { if } F \geq \Pi_{2}\left(k^{C}(c, r) \mid c_{1}, c_{2}, r, 0\right) .\end{cases}
$$

Note that for $k_{1}>k^{J}\left(c_{1}, c_{2}, r\right)$ the follower's capacity best-response $R^{0}\left(k_{1}\right)$ is constant at the level $\lambda_{2}\left(c_{1}, c_{2}, r\right)$, and that $R^{0}\left(k_{1}\right)$ lies in region $B_{4}$, where subgame equilibrium profits are independent of $k_{1}$. Consequently, if $F<\Pi_{2}\left(k^{J}, \lambda_{2} \mid c_{1}, c_{2}, r, 0\right)$, then $R\left(k_{1}\right)$ coincides with the expression for $R^{0}\left(k_{1}\right)$ given in equation (6). When $\Pi_{2}\left(k^{J}, \lambda_{2} \mid c_{1}, c_{2}, r, 0\right) \leq F<\Pi_{2}\left(k^{C}(c, r) \mid c_{1}, c_{2}, r, 0\right)$, the jump point $\mathrm{k}^{\mathrm{m}}$ lies on the second branch of $\mathrm{R}^{0}\left(\mathrm{k}_{1}\right)$ in equation (6). Finally, when $\mathrm{F} \geq \Pi_{2}\left(\mathrm{k}^{\mathrm{C}}(\mathrm{c}, \mathrm{r})\right.$ । $\left.c_{1}, c_{2}, r, 0\right)$, the jump point occurs to the left of $k_{1}^{C}(c, r)$, so that $R\left(k_{1}\right)$ is equal to $Q_{2}^{F}\left(k_{1}\right)$.

The remaining two propositions parallel Proposition 3.

${ }^{28}$ The function $\eta\left(c_{1}, c_{2}, r, F\right)$ below is strictly decreasing in $F$ and is given by the positive root of the following quadratic equation in $k_{1}: 16\left(c_{1}-c_{2}-r\right)^{3} k_{1}^{2}+\left[8\left(1-c_{1}\right)^{2}\left(c_{1}-c_{2}-r\right)^{2}-\right.$ $\left.36\left(1-c_{1}\right)\left(c_{1}-c_{2}-r\right) F+27 F^{2}\right] k_{1}+\left(1-c_{1}\right)^{3}\left[\left(1-c_{1}\right)\left(c_{1}-c_{2}-r\right)-F\right]=0$. 
Proposition 6: Suppose $\mathrm{r}<\left(1-2 \mathrm{c}_{2}+\mathrm{c}_{1}\right) / 2, \mathrm{c}_{2}<\mathrm{c}_{1}-\Delta\left(\mathrm{c}_{1}, \mathrm{r}\right)$, and $\mathrm{d}\left(\mathrm{c}_{1}\right)\left(\mathrm{c}_{1}-\mathrm{c}_{2}-\mathrm{r}\right)<$ $\Pi_{2}\left(k^{C}(c, r) \mid c_{1}, c_{2}, r, 0\right)$. Then

$$
R\left(k_{1}\right)= \begin{cases}R^{0}\left(k_{1}\right) & \text { if } k_{1}<k^{m} \\ 0 & \text { if } k_{1} \geq k^{m}\end{cases}
$$

where

$$
\mathrm{k}^{\mathrm{m}}= \begin{cases}\infty & \text { if } \mathrm{d}\left(\mathrm{c}_{1}\right)\left(\mathrm{c}_{1}-\mathrm{c}_{2}-\mathrm{r}\right)>\mathrm{F} \\ \eta\left(c_{1}, c_{2}, \mathrm{r}, \mathrm{F}\right) & \text { if } \mathrm{d}\left(\mathrm{c}_{1}\right)\left(\mathrm{c}_{1}-\mathrm{c}_{2}-\mathrm{r}\right) \leq \mathrm{F}<\Pi_{2}\left(\mathrm{k} \mathrm{C}(\mathrm{c}, \mathrm{r}) \mid c_{1}, \mathrm{c}_{2}, \mathrm{r}, 0\right) \\ 1-c_{2}-\mathrm{r}-2 \sqrt{\mathrm{F}} & \text { if } \mathrm{F} \geq \Pi_{2}\left(\mathrm{k}^{\mathrm{C}}(\mathrm{c}, \mathrm{r}) \mid c_{1}, \mathrm{c}_{2}, \mathrm{r}, 0\right) .\end{cases}
$$

In Proposition 6, when $F<d\left(c_{1}\right)\left(c_{1}-c_{2}-r\right), R\left(k_{1}\right)$ coincides with $R^{0}\left(k_{1}\right)$. Fixed costs are then small enough that for $\mathrm{k}_{1}>\mathrm{k}^{\mathrm{u}}$ the follower prefers to price the leader out of the market rather than staying out itself. When $\mathrm{d}\left(\mathrm{c}_{1}\right)\left(\mathrm{c}_{1}-\mathrm{c}_{2}-\mathrm{r}\right) \leq \mathrm{F}<\Pi_{2}\left(\mathrm{k}^{\mathrm{C}}(\mathrm{c}, \mathrm{r}) \mid \mathrm{c}_{1}, \mathrm{c}_{2}, \mathrm{r}, 0\right)$, the jump point occurs on the upward-sloping branch of $\mathrm{R}^{0}\left(\mathrm{k}_{1}\right)$ given by the middle expression in (6). Finally, when $\mathrm{F} \geq \Pi_{2}\left(\mathrm{k}^{\mathrm{C}}(\mathrm{c}, \mathrm{r}) \mid \mathrm{c}_{1}, \mathrm{c}_{2}, \mathrm{r}, 0\right), \mathrm{R}\left(\mathrm{k}_{1}\right)=\mathrm{Q}_{2}^{\mathrm{F}}\left(\mathrm{k}_{1}\right)$.

In Proposition $7 \mathrm{k}^{\mathrm{u}} \leq \mathrm{k}_{1}^{\mathrm{C}}(\mathrm{c}, \mathrm{r})$, so that $\mathrm{R}^{0}\left(\mathrm{k}_{1}\right)$ contains no upward-sloping branch.

Proposition 7: Suppose $\mathrm{r}<\left(1-2 \mathrm{c}_{2}+\mathrm{c}_{1}\right) / 2, \mathrm{c}_{2}<\mathrm{c}_{1}-\Delta\left(\mathrm{c}_{1}, \mathrm{r}\right)$, and $\mathrm{d}\left(\mathrm{c}_{1}\right)\left(\mathrm{c}_{1}-\mathrm{c}_{2}-\mathrm{r}\right) \geq$ $\Pi_{2}\left(k_{2}^{\mathrm{C}}(\mathrm{c}, \mathrm{r}) \mid \mathrm{c}_{1}, \mathrm{c}_{2}, \mathrm{r}, 0\right)$. Then

$$
R\left(k_{1}\right)= \begin{cases}R^{0}\left(k_{1}\right) & \text { if } k_{1}<k^{m} \\ 0 & \text { if } k_{1} \geq k^{m}\end{cases}
$$

where 


$$
\mathrm{k}^{\mathrm{m}}= \begin{cases}\infty & \text { if } \mathrm{d}\left(\mathrm{c}_{1}\right)\left(c_{1}-\mathrm{c}_{2}-\mathrm{r}\right)>\mathrm{F} \\ 1-c_{2}-\mathrm{r}-2 \sqrt{\mathrm{F}} & \text { if } \mathrm{F} \geq \mathrm{d}\left(\mathrm{c}_{1}\right)\left(c_{1}-c_{2}-\mathrm{r}\right)\end{cases}
$$

This case differs from the case treated in Proposition 6 because $R^{0}\left(k_{1}\right)$ jumps directly from region $A$ to region $C$. If $F<d\left(c_{1}\right)\left(c_{1}-c_{2}-r\right)$, there is no change in the follower's capacity best response. If this inequality is reversed, $R\left(k_{1}\right)=Q_{2}^{F}\left(k_{1}\right)$.

\section{Entry Accommodation and Deterrence}

The analysis of the follower's best-response function in Section 4 now allows us to examine the optimal choice of capacity by the leader and thus the potential for entry deterrence. The leader chooses the capacity $k_{1}$ that maximizes the profit $\Pi_{1}\left(k_{1}, R\left(k_{1}\right) l c_{1}, c_{2}, r, F\right)$ obtained when the follower responds with $\mathrm{R}\left(\mathrm{k}_{1}\right)$. Following Bain (1956) we distinguish between capacity choices for which entry is accommodated, blockaded, or deterred. Entry is said to be accommodated if the capacity choice of the incumbent is such that the optimal response of the follower is to choose a positive capacity. Entry is blockaded if the incumbent's monopoly capacity $Q_{1}^{r}(0)$ for unit cost $c_{1}+r-i . e .$, the capacity it would set in the absence of the threat of entry - suffices to induce the follower to respond with zero capacity and hence stay out of the market. Entry is deterred if it is optimal for the incumbent to strategically set a capacity greater than $Q_{1}^{r}(0)$ in order to induce the follower to respond by setting zero capacity.

Depending on the assumed values of the cost parameters, our model obtains a wide range of qualitatively distinct outcomes in the three-stage game. Entry is accommodated when the fixed set-up cost $F$ is sufficiently small given the differences (which cannot be drastic) in the unit costs of production up to capacity and the cost of capacity. In the case of accommodated entry, the incumbent may behave according to the Sylos postulate, so that price is driven down to a level that clears all capacity, or it may provide a stochastic price umbrella under which the entrant can pick prices. The cost of capacity and the unit costs of production up to capacity determine which outcome occurs. For high capacity costs, entry accommodation (when it 
occurs) leads to Stackelberg behavior. For low capacity costs, the nature of equilibrium depends on unit production cost asymmetries. Judo-like behavior arises if the incumbent has the lower cost of production or if it is not too cost disadvantaged. In judo equilibrium, the incumbent sets a large capacity and the entrant a small capacity, so that a nondegenerate mixed strategy arises at the price-setting stage. In this equilibrium the incumbent sets higher prices on average than the entrant, and both stochastically reduce output below capacity. When capacity costs are low and the incumbent is sufficiently cost disadvantaged, the incumbent must reduce its capacity below the Stackelberg level to avoid facing an aggressive capacity response by the entrant and hence the possibility of being driven out of the market at the price-setting stage. The entrant, firm 2 , responds by setting capacity along $Q_{2}^{\mathrm{T}}\left(\mathrm{k}_{1}\right)$, so that in equilibrium both firms produce at full capacity. We call this type of outcome a reverse judo result. Finally, when the capacity cost is low and the incumbent has a moderate cost disadvantage or when capacity costs are intermediate and the firms' unit costs are not too different, entry accommodation yields $k_{1}^{C}(c, r)$ as the leader's capacity. The follower responds with $k_{2}^{C}(c, r)$ and firms set prices to clear all capacity from the market. Hence we obtain equilibria with capacities between the Cournot levels $k_{i}^{C}(r, r), i=1,2$ and the Stackelberg levels $k_{i}^{s}(r, r), i=1,2$. These correspond to the equilibria in Dixit's (1980) quantity-setting model.

Figures $6 \mathrm{a}$ and $6 \mathrm{~b}$ show the qualitatively distinct ranges of accommodating equilibria as the difference in the unit production costs of the two firms and the cost of capacity vary. Figure 6a illustrates the nature of equilibrium as a function of $r$ and $c_{1}$, holding $F=c_{2}=0$. In this case the entrant is cost advantaged. Figure $6 \mathrm{~b}$ illustrates the type of equilibrium as a function of $r$ and $c_{2}$, holding $F=c_{1}=0$. In this case the incumbent is cost advantaged.

To understand how to match the qualitative information contained in these pictures with the analysis of the capacity best-response functions in the previous section, consider Figure 6a. When $c_{1}=r=0$, firm 2's best-response function is given by Proposition 2, as illustrated in Figure 5c. Along this best-response function, firm 1 clearly optimizes by selecting either $k_{1}^{C}(c, r)$ or $k^{J}$. When $c_{1}=0$, the middle branch of $R^{0}\left(k_{1}\right)$ is actually flat, since in region $B_{3}$ firm 2's profits are 
given by $\mathrm{k}_{2} \mathrm{H}_{1}^{*}\left(\mathrm{k}_{2}\right) / \mathrm{k}_{1}$. Firm 1 is therefore indifferent between $\mathrm{k}_{1}^{\mathrm{C}}(\mathrm{c}, \mathrm{r})$ and any other point along the middle branch of $R^{0}\left(k_{1}\right)$. At $k_{1}=k^{J}$, firm 2's capacity jumps down to the judo level $\lambda_{2}$, making $k_{1}=k^{\mathrm{J}}$ the optimal choice at $c_{1}=0 .{ }^{29}$ As $c_{1}$ increases, $\lambda_{2}$ increases, making firm 1 eventually prefer $k_{1}=k_{1}^{C}(c, r)$. The nature of the equilibrium then shifts from a judo equilibrium to a pure strategy equilibrium between the Cournot and Stackelberg levels $k_{1}^{C}(r, r)$ and $k_{1}^{s}(r, r)$. As $c_{1}$ further increases, the best-response function becomes that given in Proposition 3. As long as $k^{\mathbf{u}} \geq k_{1}^{C}(c, r)$, the equilibria remain of the Dixit type. For $c_{1}$ sufficiently large, however, $k^{\mathbf{u}}<$ $\mathrm{k}_{1}^{\mathrm{C}}(\mathrm{c}, \mathrm{r})$, and firm 2's best-response function is as indicated in Figure 5e. Firm 1 then optimizes by choosing $\mathrm{k}_{1}=\mathrm{k}^{\mathrm{u}}$, resulting in a reverse judo equilibrium. As $\mathrm{c}_{1}$ further increases, $\mathrm{k}^{\mathrm{u}}$ converges to zero, eventually yielding firm 2 a monopoly position.

If we start at the origin of Figure 6a, but instead gradually raise $r$, then as argued above the equilibrium is initially of the judo type. As $r$ is increased, $R^{0}\left(k_{1}\right)$ shifts down, and $k_{1}^{C}(c, r)$ eventually becomes the preferred point. This again leads to pure strategy equilibria akin to the equilibria in Dixit's (1980) quantity-setting model. Further increases in $r$ eventually push $k_{1}^{C}(c, r)$ beyond the Stackelberg point on $Q_{2}^{r}\left(k_{1}\right)$, resulting in the Stackelberg outcome. The analysis of the remainder of Figures $6 \mathrm{a}$ and $6 \mathrm{~b}$ is similar.

Since the fixed set-up cost parameter $F$ only affects the entrant's decision to enter the market, changes in $F$ affect accommodating equilibria only insofar as the incumbent's choice of whether to accommodate or prevent entry (or possibly to stay out itself) is altered. Hence, conditional on accommodation arising, the characterization of the equilibria in Figures $6 \mathrm{a}$ and $6 \mathrm{~b}$ will hold for other values of $F$ as well.

As is evident from the figures, the Bertrand-Edgeworth approach provides a useful gametheoretic model in which seemingly disparate entry equilibria that have previously appeared in the literature are obtained as subgame perfect equilibria for different ranges of the cost

${ }^{29}$ Since capacity costs are zero, values of $\mathrm{k}_{1}$ exceeding $\mathrm{k}^{\mathrm{J}}$ are also optimal. However, such responses necessarily disappear when $\mathrm{r}$ becomes even slightly positive, and we therefore ignore them in our discussion. 
parameters $c_{1}, c_{2}, r$, and $F$. Stackelberg's quantity-setting solution arises for accommodating equilibria involving a large cost of capacity. Lower costs of capacity may be associated with equilibria similar to the quantity-setting equilibria advocated by Dixit (1980), with stochastic price-setting versions of the judo equilibria presented in Gelman and Salop (1983), or with the reverse judo equilibria of Deneckere and Kovenock (1989a,b) and Faith (1990). Which of these qualitatively distinct equilibria arises is determined by unit cost asymmetries and the cost of capacity.

Entry is deterred in our model when the fixed cost $\mathrm{F}$ is sufficiently large to make deterrence more profitable than accommodation, but sufficiently small so as to preclude blockaded entry. When entry is successfully deterred, excessive capacity built to deter entry may be utilized completely or may be left partially idle. Hence, unlike models in previous papers in the literature, our model provides support for the use of idle capacity to deter entry, while maintaining a post-entry simultaneous move structure, subgame perfection, and standard assumptions on demand (such as linearity). Idle capacity is more likely with a more efficient incumbent than a less efficient one (as measured by unit cost of production up to capacity) and is more likely the lower the cost of capacity. Excessive, but fully utilized, capacity is more likely to be chosen as a preemptive strategy the higher the cost of capacity and the higher the fixed setup costs.

To illustrate the type of outcomes that might arise, consider the four capacity bestresponse functions $R\left(k_{1}\right)$ shown in Figure 7. These represent best-response functions for $c_{1}=0, c_{2}=0$, and $r=.05$. Figure $7 \mathrm{a}$ shows a case where the fixed cost $\mathrm{F}$ is less than $\Pi_{2}\left(k^{J}, \lambda_{2} \mid c_{1}, c_{2}, r, 0\right)$ and entry is accommodated. The cost of capacity and the fixed cost are sufficiently small that a judo outcome arises in which the leader sets a large capacity and the follower a small capacity, and the leader provides a stochastic price umbrella under which the follower prices. The dashed lines in the figure illustrate $Q_{i}^{c}\left(k_{j}\right), i=1,2$. Figure $7 b$ illustrates a case in which $F$ is sufficiently large that $R\left(k_{1}\right)$ jumps down at a point $k^{m}>Q_{1}^{c}(0)$. In this case firm 1 chooses $\mathrm{k}^{\mathrm{m}}$ as its capacity and firm 2 responds with $\mathrm{k}_{2}=0$. In the final price-setting 
stage, firm 1 sets price equal to $P\left(Q_{1}^{c}(0)\right)$, the monopoly price for unit cost $c_{1}$. Entry is deterred with excess capacity $\left(k^{m}-Q_{1}^{r}(0)\right)$, some of which $\left(k^{m}-Q_{1}^{c}(0)\right)$ is left idle.

In Figure 7c the jump point $\mathrm{k}^{\mathrm{m}}$ lies between $Q_{1}^{\mathrm{r}}(0)$ and $\mathrm{Q}_{1}^{\mathrm{c}}(0)$. It is optimal for firm 1 to set $\mathrm{k}_{1}=\mathrm{k}^{\mathrm{m}}$ and deter entry. Since, when faced with a unit cost of production up to capacity of $c_{1}$, firm 1 would like to produce $Q_{1}^{c}(0)$, it produces at full capacity $q_{1}=k^{m}$. Entry is deterred with excess capacity $\left(\mathrm{k}^{\mathrm{m}}-\mathrm{Q}_{1}^{\mathrm{r}}(0)\right)$ that is fully utilized. $\mathrm{It}$ is interesting to note that a necessary condition for entry to be deterred with excessive but fully utilized capacity is that the cost of capacity be positive. This insures that $Q_{1}^{\mathfrak{T}}(0)<Q_{1}^{\mathfrak{c}}(0)$. The last frame of Figure 7 illustrates the case where $F$ is sufficiently large that entry is blockaded, $\mathrm{k}^{\mathrm{m}} \leq Q_{1}^{\mathrm{T}}(0)$. In this case firm 1 sets capacity $k_{1}=Q_{1}^{r}(0)$ and prices at $P\left(Q_{1}^{r}(0)\right.$ ).

Figure 8 shows the qualitative nature of the equilibria that arise for $c_{1}=c_{2}=0$ and different $(r, F)$ pairs. The values of $r$ and $F$ corresponding to Figures $7(a)$ - (d) are labeled (a) -. (d). As these pictures show, larger unit costs of capacity are associated with smaller values of the fixed set-up cost $\mathrm{F}$ that defines the boundary between regions where entry does and does not occur. However, when entry is accommodated, the fixed cost $\mathrm{F}$ is not relevant in determining the boundary between the regions of qualitatively different outcomes.

When entry is deterred, for any $(r, F)$ pair for which idle capacity arises there is an $r^{\prime}>r$ such that $\left(r^{\prime}, F\right)$ generates excessive but not idle capacity to deter entry. Correspondingly, for $r>0$ there is an $F^{\prime}>F$ such that $\left(r, F^{\prime}\right)$ generates excessive but not idle capacity. The range of $(r, F)$ pairs for which entry is deterred with excessive but not idle capacity lies to the north and east of the idle capacity range in $(\mathrm{r}, \mathrm{F})$ space.

For general $\left(c_{1}, c_{2}, r\right)$ triples, when the cost of capacity is sufficiently large, entry deterring equilibria correspond to those of the Stackelberg model and hence never involve idle capacity. Entry deterrence with idle capacity requires that the incumbent set a capacity greater than $Q_{1}^{c}(0)$, which is never profitable for $\mathrm{r}$ large enough to generate a Proposition 1 best-response function, $R^{0}\left(k_{1}\right)$. A necessary condition for idle capacity to arise in entry deterrence is that $R^{0}\left(k_{1}\right)$ be a Proposition 2 or 3 best response function. For Proposition 2 best-response functions, idle 
capacity to deter entry requires $\mathrm{k}^{\mathrm{m}} \in\left(\mathrm{Q}_{1}^{\mathrm{c}}(0), \mathrm{k}^{\mathrm{J}}\right]$. For Proposition 3 best-response functions, idle capacity to deter entry requires $k^{\mathrm{u}}>Q_{1}^{c}(0)$ and $k^{m} \in\left(Q_{1}^{c}(0), k^{u}\right]$. Figures 9-11 depict the qualitative nature of equilibria in $(F, r)$ space for $\left(c_{1}, c_{2}\right)=(0, .1),(.1,0)$, and $(.3,0)$ respectively.

\section{Conclusion}

Since its inception, oligopoly theory has relied heavily on quantity-setting models of competition. With the emphasis on extensive form modelling of oligopoly games that coincided with the birth of the "new" theoretical industrial organization, the timing of firms' strategic choices received more scrutiny. The basic observation that firms set prices as well as quantities calls into question the use of the Cournot model as a reasonable reduced form for a more complicated process of strategic interaction. In a seminal paper, Kreps and Scheinkman (1983) showed that it was possible to obtain the Cournot outcome as a reduced form for a more complicated process of simultaneous capacity setting followed by simultaneous price-setting. This framework had popular appeal because it separated the quantity and pricing decisions of firms and made the intuitively appealing assumption (at least for many markets) that prices can more easily be set contingent on capacities than vice versa. At the same time, the approach lent guarded support for the use of the Cournot equilibrium in modelling market behavior under imperfect competition.

This paper takes the Bertrand-Edgeworth philosophy a step further by attempting to apply the approach to one of the fundamental theoretical issues of industrial organization, the profitability of credible precommitment to deter entry. In doing so, we provide a new and intuitive answer to the question addressed in the literature on entry deterrence of whether it is desirable to hold idle capacity to deter entry. We also provide a unified framework in which several qualitatively distinct outcomes (some of which have been proposed previously in the literature) appear as special cases.

To understand the origins of this chameleon-like character of the Bertrand-Edgeworth model, it is useful to examine how the degree of post-entry competition influences the outcome 
of the capacity precommitment game. Price-taking behavior in the post-entry game provides an interesting benchmark because it appears at one extreme of the behavioral spectrum. With equal marginal production costs, perfectly competitive pricing also ensures that firms will produce at full capacity in the post-entry game. Vigorous post-entry competition thus renders the outcomes favored by Sylos-Labini (1969) and Spence (1977) immune to the Dixit (1979) critique. ${ }^{30}$ Another alternative that merits attention is post-entry quantity competition, if only because this case has figured so prominently in the entry deterrence literature.

Figures 12 and 13 are the analogues to Figures $6 a$ and $6 b$, drawn under different assumptions on post-entry competition. Panel (a) illustrates the outcomes of Dixit's two-stage game $^{31}$ and panel (b) those of the three-stage game with perfectly competitive pricing in the final stage. A glance at these pictures reveals an amazing similarity with Figures $6 \mathrm{a}$ and $6 \mathrm{~b}$. In fact, superimposing panels (a) and (b) in Figure 12 (13) reveals many common boundaries with Figures 6a (6b). With the exception of the judo region, the outcomes under Bertrand-Edgeworth competition thus coincide alternately with the outcome under perfect competition or Cournot post-entry competition. ${ }^{32}$

To see why the Bertrand-Edgeworth model sometimes takes on the character of the perfectly competitive pricing model, at other times mimics the behavior of the quantity-setting model, and at still other times produces behavior which has no equivalent in either model, it is useful to compare the respective capacity best-response functions. Figure 14a illustrates the case

${ }^{30}$ One paper that models competition in this way is Dixon (1985).

${ }^{31}$ As shown by Ware (1985), Dixit's assumption that the entrant and incumbent simultaneously select their output in the second stage of the game is not innocuous. This assumption allows the incumbent to precommit to output before the entrant has committed its capacity. Ware shows that in a three-stage game the possibilities for deterrence are more limited than Dixit suggests. Outcomes close to the point V in Dixit's diagram are eliminated because the entrant can select a capacity slightly above the quantity best-response function and induce the incumbent to produce below capacity in the quantity-setting subgame.

${ }^{32}$ Note that it is not merely the case that whenever the two other modes of competition agree in their predictions the Bertrand-Edgeworth model concurs. Indeed, in Figure $6 \mathrm{~b}$, judo behavior displaces an area of common Stackelberg behavior in panels (a) and (b) of Figure 13. 
of a more efficient leader, with parameter configurations such that the equilibrium falls in the judo region of Figure $6 \mathrm{~b}$ (but below the continuation of the upper boundary of the Dixit region). As explained in Section 5, with Bertrand-Edgeworth competition, judo behavior displaces quantity-setting behavior because to the right of the point $\mathrm{V}$, capacity increases by firm 1 serve only to reduce firm 2's post-entry profit. Under quantity competition, such expansion has no effect, because it will never be used in the post-entry game. The follower thus responds less aggressively under Bertrand-Edgeworth competition than under Cournot competition. In this case, the Bertrand-Edgeworth model deters entry more effectively than the quantity-setting model. $^{33}$

Figure 14a also reveals that the Sylos postulate and price-taking behavior result in identical capacity best-response functions. However, the outcomes under the two modes of behavior do not coincide. The Sylos postulate produces the Stackelberg outcome, while pricetaking behavior results in entry being deterred, with the incumbent holding idle capacity. The reason for this discrepancy is that with price-taking behavior the incumbent's profits are not continuous at $k_{2}=0$ : in the absence of entry, the incumbent can produce at the monopoly level, whereas small-scale entry forces the incumbent to utilize all available capacity. As a result, the incumbent's behavior under Bertrand-Edgeworth competition is less aggressive than under pricetaking behavior. A comparison with the outcome under the Sylos postulate is ambiguous. ${ }^{34}$

${ }^{33}$ When capacity costs are sufficiently high, expansion to the judo point is no longer optimal; the incumbent then behaves as in Dixit's model. One of the surprising results of our paper is that it is never optimal for the incumbent to choose a capacity strictly between $k_{1}^{C}(c, r)$ and $k_{1}^{J}$ when $F=0$. Intuitively, this is because for low capacity costs the discontinuity in the best-response function makes it optimal to expand to $k_{1}^{J}$, while for high capacity costs the marginal benefit of expansion inside region $B_{3}$ exceeds the marginal cost.

${ }^{34}$ As illustrated in Figure 14a, judo behavior may lead to more aggressive incumbent behavior than under the Sylos postulate. However, the area of the judo region to the right of the dashed line in Figure $6 \mathrm{~b}$ has $\mathrm{k}_{2}^{\mathrm{s}}=0$, resulting in the opposite ranking. 
Figures $14 \mathrm{~b}$ and $\mathrm{c}$ illustrate capacity best-response functions when the leader is less efficient. ${ }^{35}$ The parameter combinations of Figure $14 \mathrm{~b}$ lie in the Dixit region of Figure 6a, and the entrant's cost advantage is sufficiently large that the Bertrand-Edgeworth capacity best response never jumps down into region $\mathbf{B}_{4}$. In this case, large incumbent capacities increase competition sufficiently to make the entrant prefer to drive the incumbent out of the market altogether. The same force is present under price-taking behavior, but the upward jump in the best-response function occurs earlier because the entrant faces more vigorous price competition. The Bertrand-Edgeworth model now behaves like the Dixit model: capacity expansion beyond the point $k_{1}^{C_{(}}(c, r)$ is never profitable since it provokes more aggressive responses. Price-taking behavior and the Sylos postulate result in successively more aggressive incumbent behavior.

Figure 14c illustrates parameter configurations such that the equilibrium falls in the reverse judo region of Figure 6a. The jump point in the Bertrand-Edgeworth and the perfectly competitive pricing model then coincide, as both lie to the left of the point $\mathrm{k}_{1}^{\mathrm{C}}(\mathrm{c}, \mathrm{r})$. In this case, the entrant behaves least aggressively under the Sylos postulate and most aggressively under Bertrand-Edgeworth competition. The capacity levels chosen by the incumbent reflect this increasing order of aggressiveness.

We conclude that price-taking and quantity-setting behavior sometimes lead to plausible market outcomes. When the outcomes under these post-entry modes of competition differ from those under Bertrand-Edgeworth competition, we believe that the Bertrand-Edgeworth approach provides a more appealing description of firm behavior.

Compared to the Bertrand-Edgeworth model, post-entry price-taking generally leads to implausibly aggressive incumbent behavior. ${ }^{36}$ Price-taking behavior allows the incumbent greater precommitment to aggressive pricing and therefore entails more passive entrant behavior.

${ }^{35}$ An example of such an industry is steel, where low-cost mini-mills have displaced higher cost incumbents in all but the highest quality steel markets.

${ }^{36}$ An exception to this rule arises in the relatively small areas of parameter space where Figures $6 \mathrm{a}$ and $\mathrm{b}$ predict the judo outcome and Figures $12 \mathrm{~b}$ and $13 \mathrm{~b}$ predict the Stackelberg outcome. 
The comparison with post-entry Cournot competition depends upon the ranking of the variable production costs. When the incumbent has a cost advantage, post-entry Cournot competition leads to implausibly passive incumbent behavior. The aggressive and symmetric price responses under Cournot competition lead the incumbent to choose relatively low quantities in the post-entry game. This makes the return to expanding capacity small. ${ }^{37}$ However, when the entrant has a sufficiently large cost advantage, the incumbent behaves implausibly aggressively under Cournot competition. The incumbent is committed to sell its quantity even if this would drive the price below its variable cost. Under Bertrand-Edgeworth competition, the entrant can price below the incumbent's variable cost without facing this incredible threat, i.e., can eliminate competition from its high-cost rival.

We conclude that the Bertrand-Edgeworth model takes on the virtues of the quantitysetting and price-taking models without inheriting their vices. By illustrating the benefits of the Bertrand-Edgeworth model, we hope to stimulate further examination of its implications for the organization of industry. We have little doubt that this will remain a fruitful area of inquiry.

${ }^{37}$ In Dixit's (1980) model, capacity expansion beyond the point $k_{1}^{C}(c, r)$ does not affect the postentry outcome. 


\section{References}

Allen, B. (1993), "Capacity Precommitment as an Entry Barrier for Price-Setting Firms," International Journal of Industrial Organization 11, 63-72.

Allen, B. and M. Hellwig (1986), "Price-Setting Firms and the Oligopolistic Foundations of Perfect Competition," American Economic Review, Papers and Proceedings, 76, 387-392.

Bain, J. S. (1956), Barriers to New Competition, Cambridge: Harvard University Press.

Basu, K. and N. Singh (1990), "Entry-Deterrence and Stackelberg Perfect Equilibria," International Economic Review 31, 61-71.

Bulow, J. , J. Geanakoplos, and P. Klemperer (1985), "Holding Idle Capacity to Deter Entry," Economic Journal 95, 178-182.

Davidson, C. and R. Deneckere (1986), "Long-Run Competition in Capacity, Short-Run Competition in Price, and the Cournot Model," Rand Journal of Economics 17, 404-415.

Deneckere, R. and D. Kovenock (1989a), "Capacity-Constrained Price Competition When Unit Costs Differ," Purdue University, Krannert Graduate School of Management Working Paper No. 958.

Deneckere, R. and D. Kovenock (1989b), "Capacity Constrained Price Competition When Unit Costs Differ," Northwestern University, (revised) CMSEMS Discussion Paper No. 861.

Deneckere, R. and D. Kovenock (1992), "Price Leadership," Review of Economic Studies 59, 143-162.

Dixit, A. (1979), "A Model of Duopoly Suggesting a Theory of Entry Barriers," Bell Journal of Economics 10(1), 20-32.

Dixit, A. (1980), "The Role of Investment in Entry Deterrence," Economic Journal 90, 95-106.

Dixon, H. (1985), "Strategic Investment in an Industry with a Competitive Product Market," Journal of Industrial Economics 33(4), 483-499.

Edgeworth, F. Y. (1925), "Pure Theory of Monopoly," in F. Y. Edgeworth, Papers Relating to Political Economy (New York: Burt Franklin), Vol. I, Chapter E, 111-142.

Faith, T. (1990), "Bertrand-Edgeworth Competition with Sequential Capacity Choice," Erasmus Universiteit Rotterdam, Econometric Institute Report 9062/A.

Fudenberg, D. and J. Tirole (1984), "The Fat Cat Effect, the Puppy Dog Ploy and the Lean and Hungry Look," American Economic Review, Papers and Proceedings, 74, 361-368.

Gelman, J. R. and S. C. Salop (1983), "Judo Economics: Capacity Competition and Coupon Competition," Bell Journal of Economics 14, 315-325.

Gilbert, R. J. (1986), "Preemptive Competition," in Stiglitz, J. E. and F. Mathewson, eds. , New Developments in the Analysis of Market Structure, Cambridge: MIT Press, 90-125. 
Hunsaker, J. (1993), "The Pattern of Exit from Declining Industries," Purdue University, Ph.D. Thesis.

Kreps, D. and J. Scheinkman (1983), "Quantity Precommitment and Bertrand Competition Yield Cournot Outcomes," Bell Journal of Economics 14, 326-337.

Kydland, F. E. and E. C. Prescott (1982), "Time to Build and Aggregate Fluctuations," Econometrica 50, 1345-1370.

Levitan, R. and M. Shubik (1972), "Price Duopoly and Capacity Constraints," International Economic Review 13(1), 111-122.

Modigliani, F. (1958), "New Developments on the Oligopoly Front," Journal of Political Economy 66(3), 215-232.

Saloner, G. (1985), "Excess Capacity as a Policing Device," Economics Letters 18, 83-86.

Scherer, F. M., A. Beckenstein, E. Kaufer, R. D. Murphy (1975), The Economics of Multi-Plant Operations, Cambridge: Harvard University Press.

Shapiro, C. (1989), "Theories of Oligopoly Behavior," in R. Schmalensee and R. D. Willig, eds., Handbook of Industrial Economics (Amsterdam: North-Holland), Chapter 6, 329-410.

Spence, A. M. (1977), "Entry, Capacity, Investment and Oligopolistic Pricing," Bell Journal of Economics 8, 534-544.

Spulber, D. F. (1981), "Capacity, Output, and Sequential Entry," American Economic Review 71, 503-514.

Stiglitz, J. E. (1987), "Technological Change, Sunk Costs, and Competition," Brookings Papers on Economic Activity 3, 883-937.

Sylos-Labini, P. (1969), Oligopoly and Technical Progress, Cambridge: Harvard University Press.

Tirole, J. (1988), The Theory of Industrial Organization, Cambridge: MIT Press.

Ware, R. (1985), "Sunk Costs and Strategic Commitment: A Proposed Three-Stage Equilibrium," Economic Journal 94, 370-378. 


\section{APPENDIX}

Nash equilibrium profits in $\mathrm{G}\left(\mathrm{k}_{1}, \mathrm{k}_{2}, \mathrm{c}_{1}, \mathrm{c}_{2}\right)$ are as follows:

(i) In region $A$ : $\quad \pi_{i}^{*}=\left(1-c_{i}-k_{1}-k_{2}\right) k_{i}, i=1,2$.

(ii) In region $B_{1}$ : $\quad \pi_{1}^{*}=k_{1}\left\{\left[1+c_{2}\right] / 2-\frac{1}{2}\left[k_{1}\left(2\left(1-c_{2}\right)-k_{1}\right)\right]^{1 / 2}-c_{1}\right\}$ and $\pi_{2}^{*}=\left[\left(1-k_{1}-c_{2}\right) / 2\right]^{2}$.

(iii) In region $B_{2}$ : $\pi_{i}^{*}=\left(k_{i} / k_{2}\right)\left[\left(1-k_{1}-c_{2}\right) / 2\right]^{2}+k_{i}\left(c_{2}-c_{i}\right), i=1,2$.

(iv) In region $B_{3}$ : $\quad \pi_{i}^{*}=\frac{k_{i}}{k_{1}}\left[\left(1-k_{2}-c_{1}\right) / 2\right]^{2}+k_{i}\left(c_{1}-c_{i}\right), i=1,2$.

(v) In region $B_{4}$ : $\quad \pi_{1}^{*}=\left[\left(1-k_{2}-c_{1}\right) / 2\right]^{2}$ and $\pi_{2}^{*}=k_{2}\left\{\left[1+c_{1}\right] / 2-(1 / 2)\left[k_{2}\left(2\left(1-c_{1}\right)-k_{2}\right)\right]^{1 / 2}-c_{2}\right\}$.

(vi) In region $\mathrm{C}$ : $\quad \pi_{\mathrm{i}}^{*}=\max \left\{0,\left[\min \left(\max \left(\frac{1+\mathrm{c}_{\mathrm{i}}}{2}, 1-\mathrm{k}_{\mathrm{i}}\right), \mathrm{c}_{\mathrm{j}}\right)-\mathrm{c}_{\mathrm{i}}\right]\right\}\left[1-\min \left(\max \left(\frac{1+\mathrm{c}_{\mathrm{i}}}{2}, 1-\mathrm{k}_{\mathrm{i}}\right), \mathrm{c}_{\mathrm{j}}\right)\right]$, $\mathrm{i}=1,2, \mathrm{j} \neq \mathrm{i}$. 


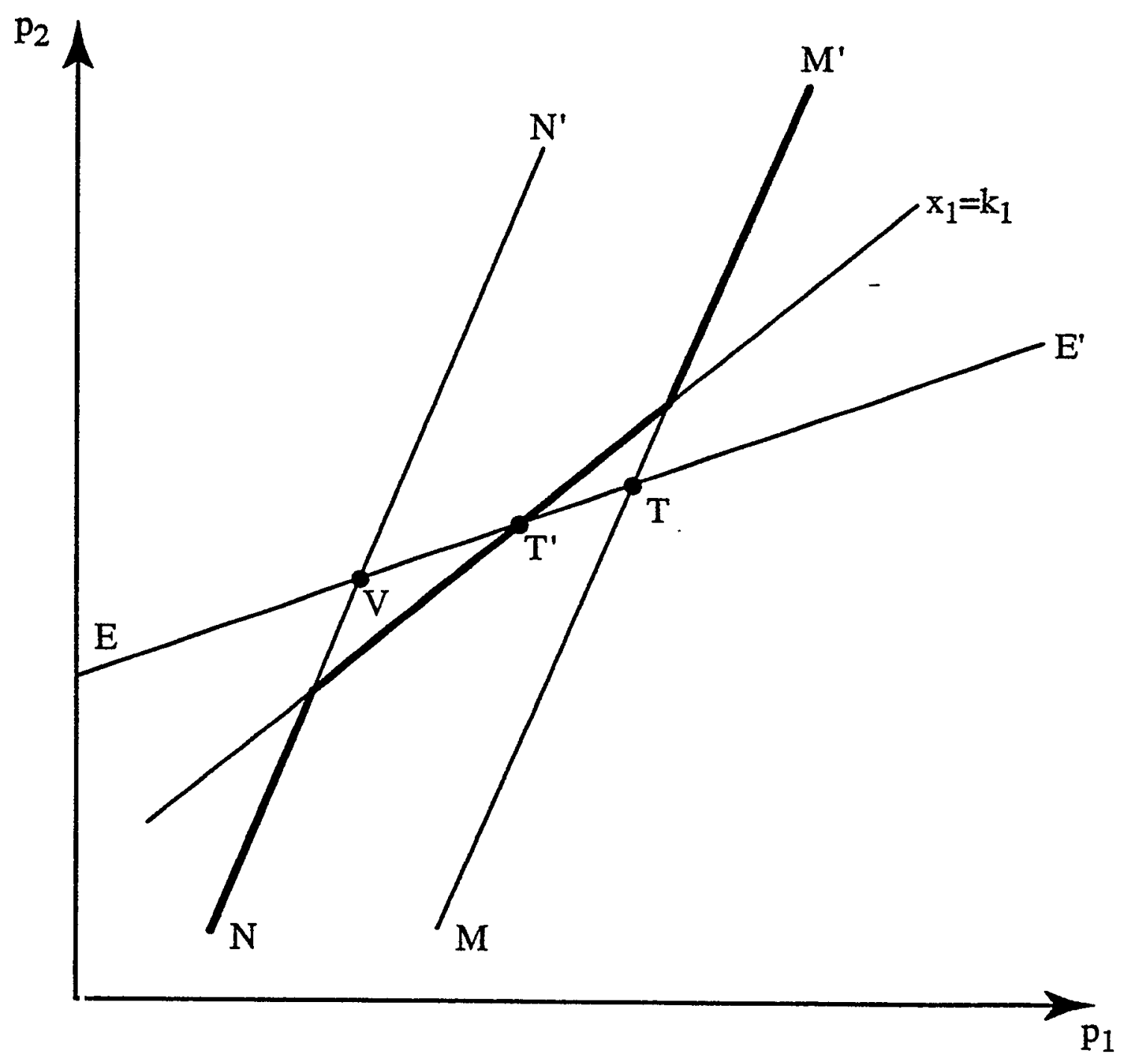

Figure 1.

The Effect of Capacity Precommitment in a Price-Setting Duopoly with No Time to Build. 


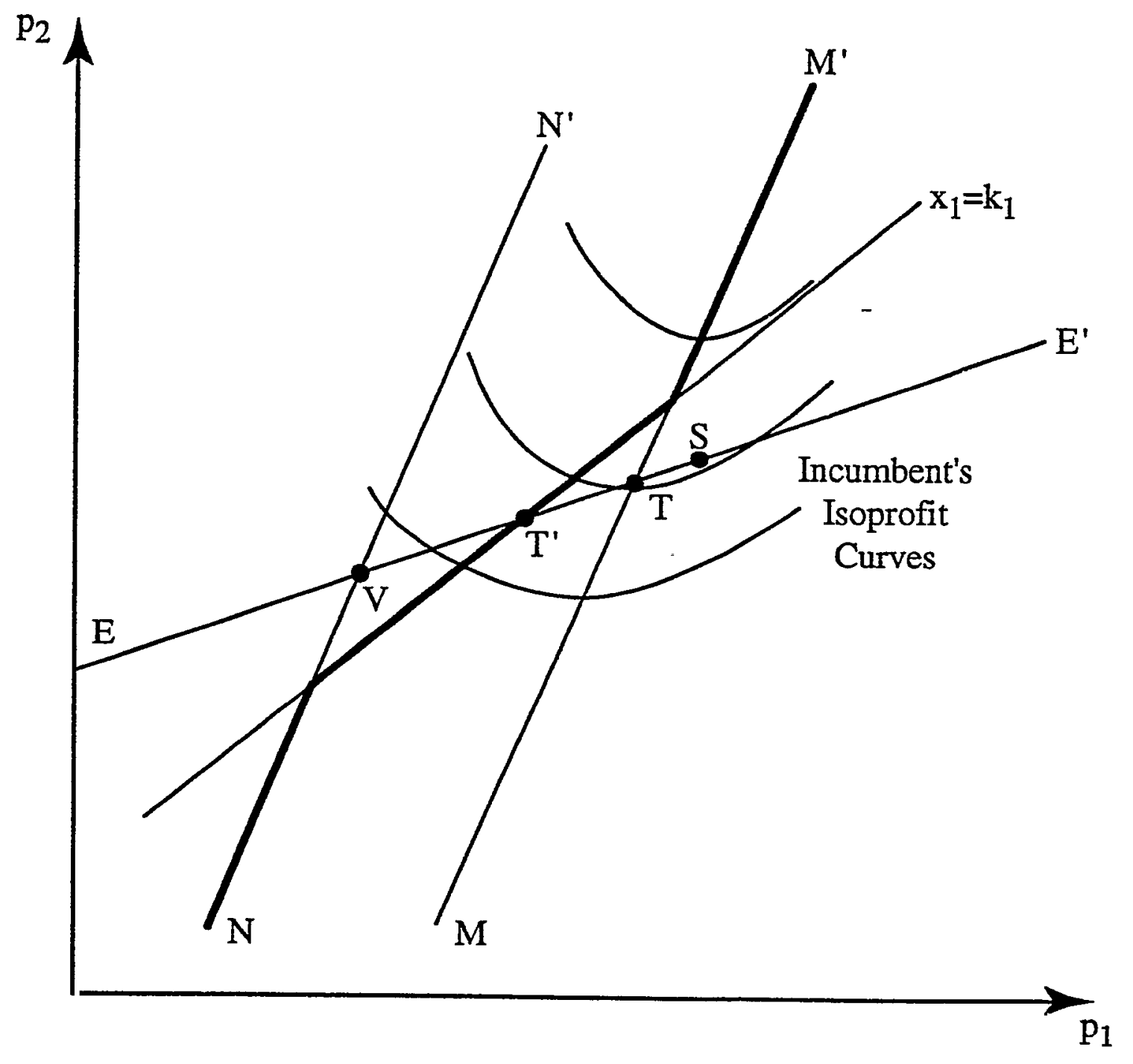

Figure 2.

The Incumbent's Preferred Outcome on the Segment TV is the Simultaneous-Move Nash Equilibrium Point $T$. 


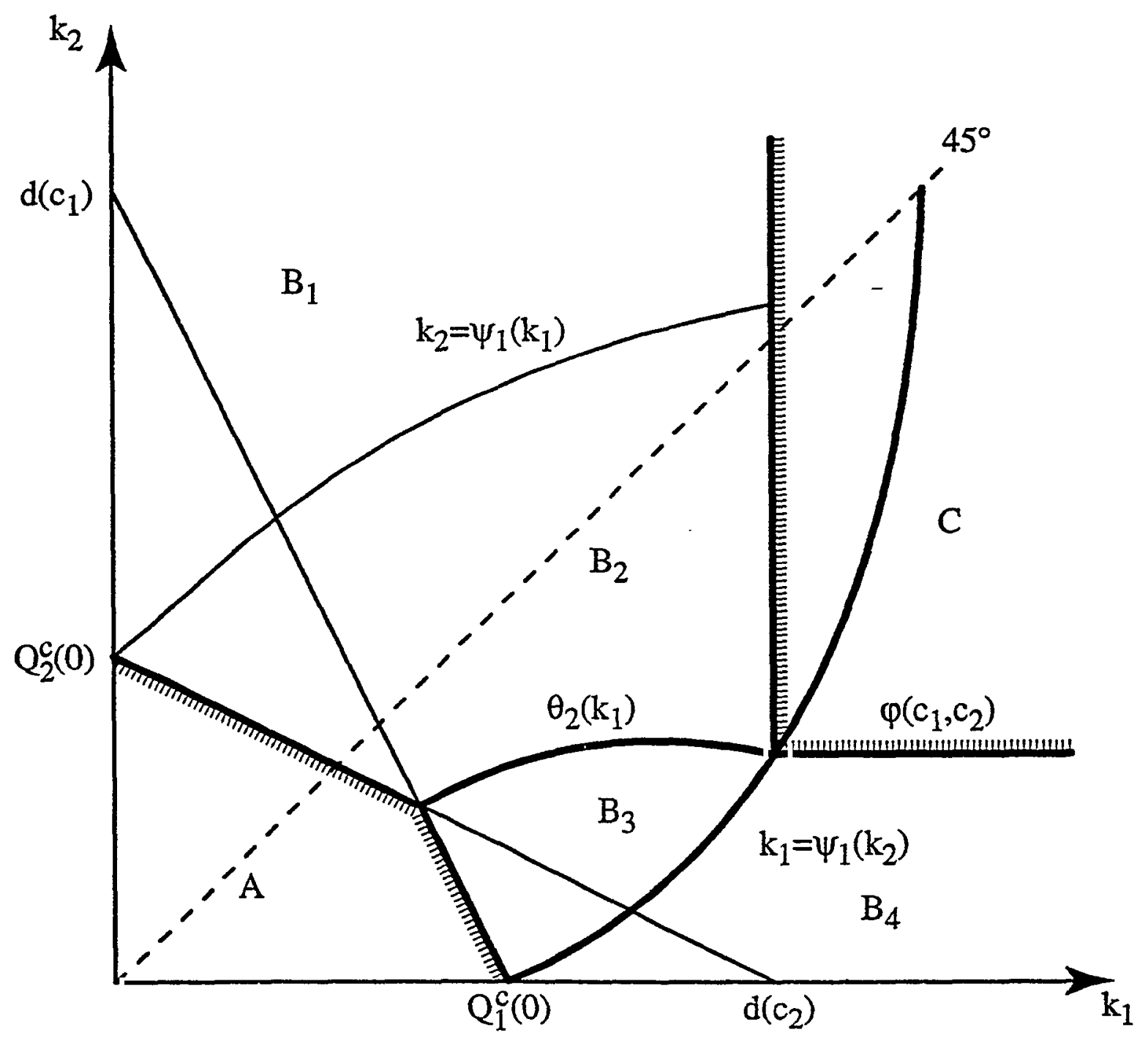

Figure 3.

Partition of the Capacity Space into Different Regions Determining the Equilibrium Profits in the Subgame $G\left(k_{1}, k_{2}, c_{1}, c_{2}\right)$ when $c_{1}<c_{2}$. 


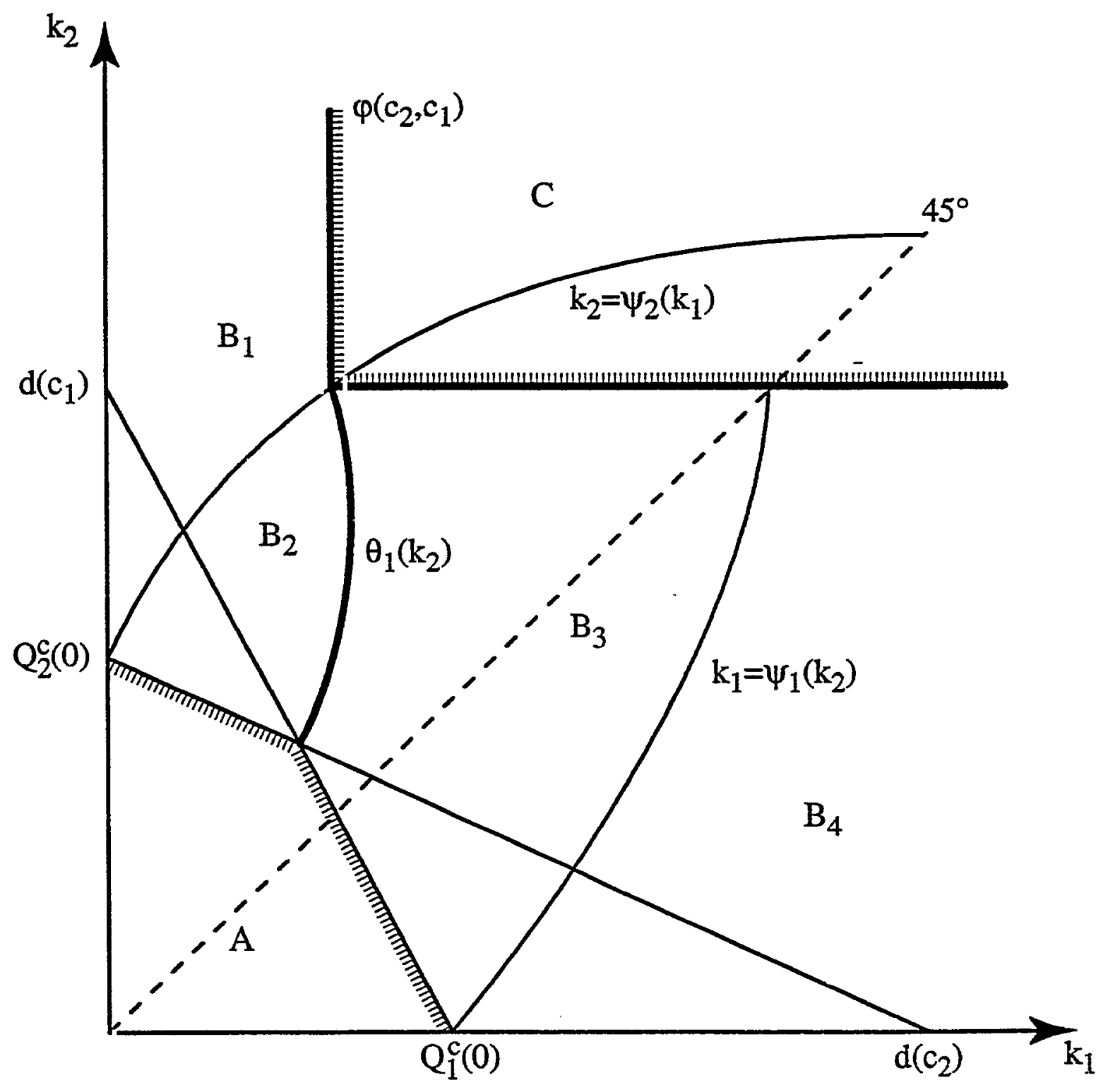

Figure 4.

Partition of the Capacity Space into Different Regions Determining the Equilibrium Profits in the Subgame $G\left(k_{1}, k_{2}, c_{1}, c_{2}\right)$ when $c_{1}>c_{2}$. 


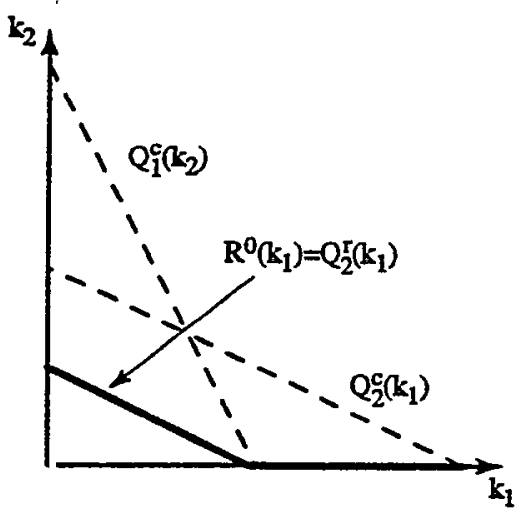

(a)

Proposition 1 Best Response Function.

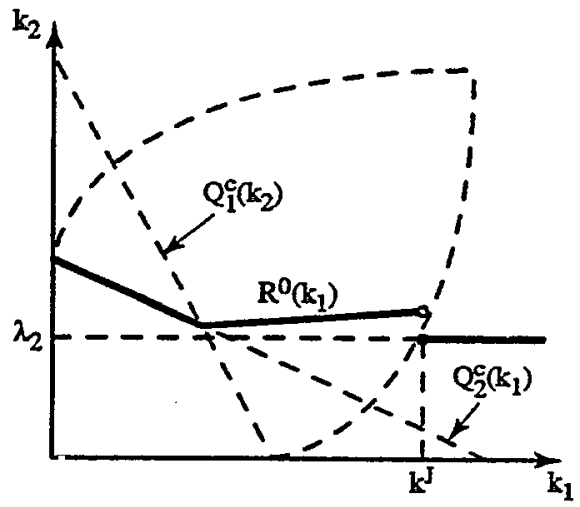

(c)

Proposition 2 Best Response Function with $c_{1}>c_{2}$

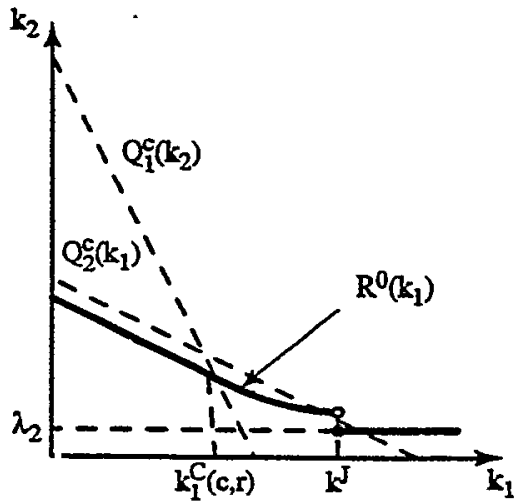

(b)

Proposition 2 Best Response Function with $c_{1}<c_{2}$.

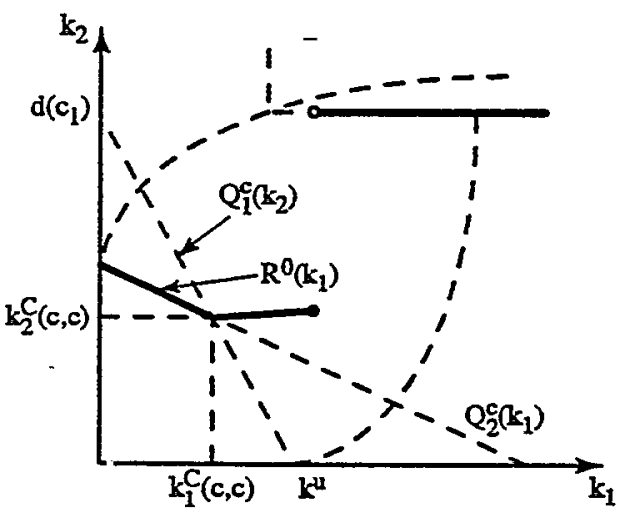

(d)

Proposition 3 Best Response Function when $k^{u}>k_{1}^{C}(c, r)$.

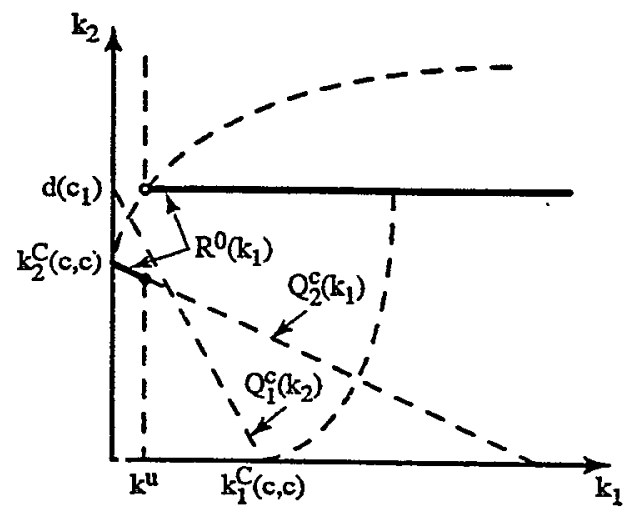

(e)

Proposition 3 Best Response Function when $\mathrm{k}^{\mathrm{u}}<\mathrm{k}_{1}^{\mathrm{C}}(\mathrm{c}, \mathrm{r})$.

Figure 5.

Capacity Best Response Functions in the Game $\Gamma\left(c_{1}, c_{2}, r, 0\right)$. 


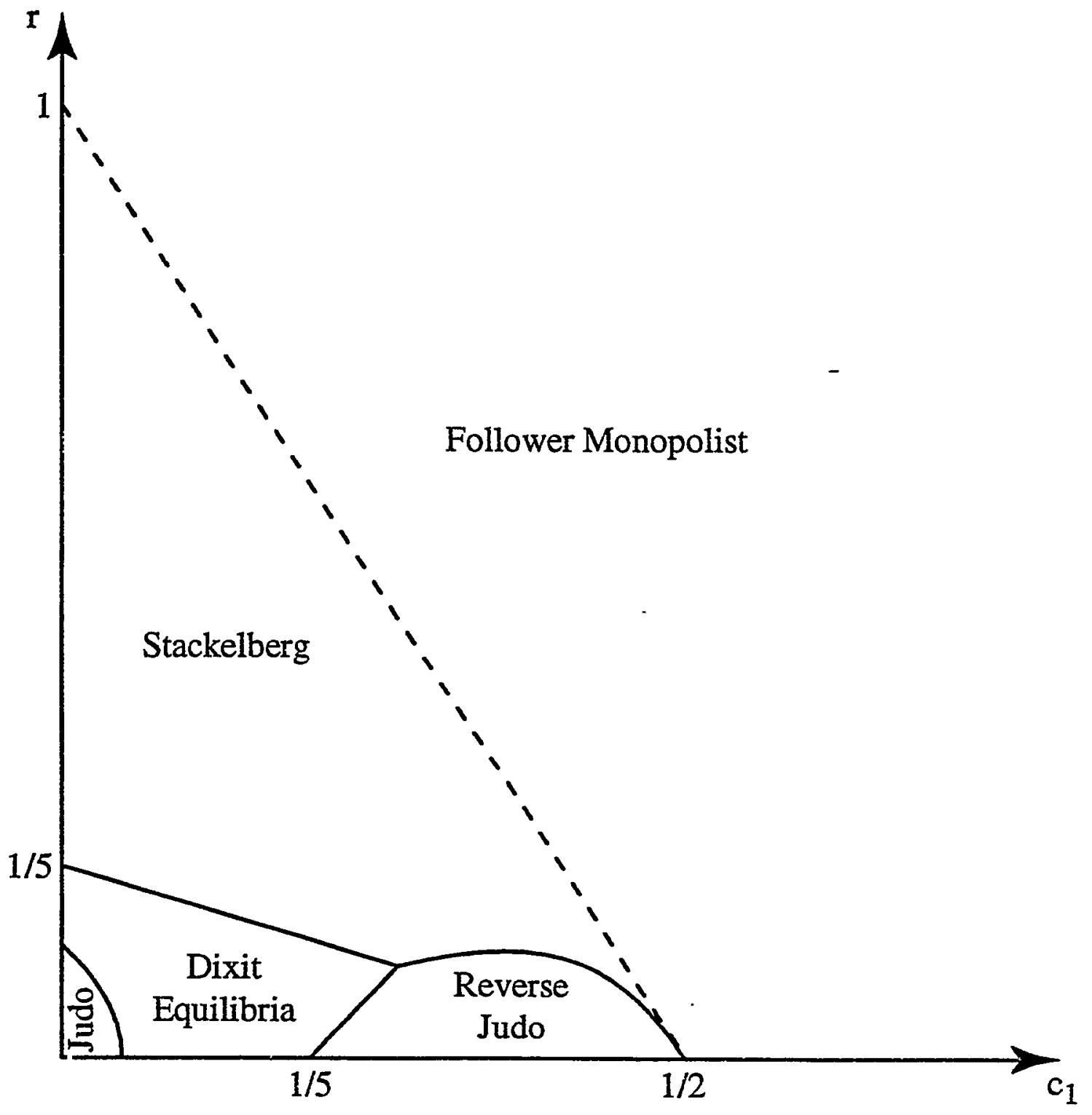

Figure 6a.

Nature of the Equilibrium in the Game $\Gamma\left(c_{1}, 0, r, 0\right)$. 


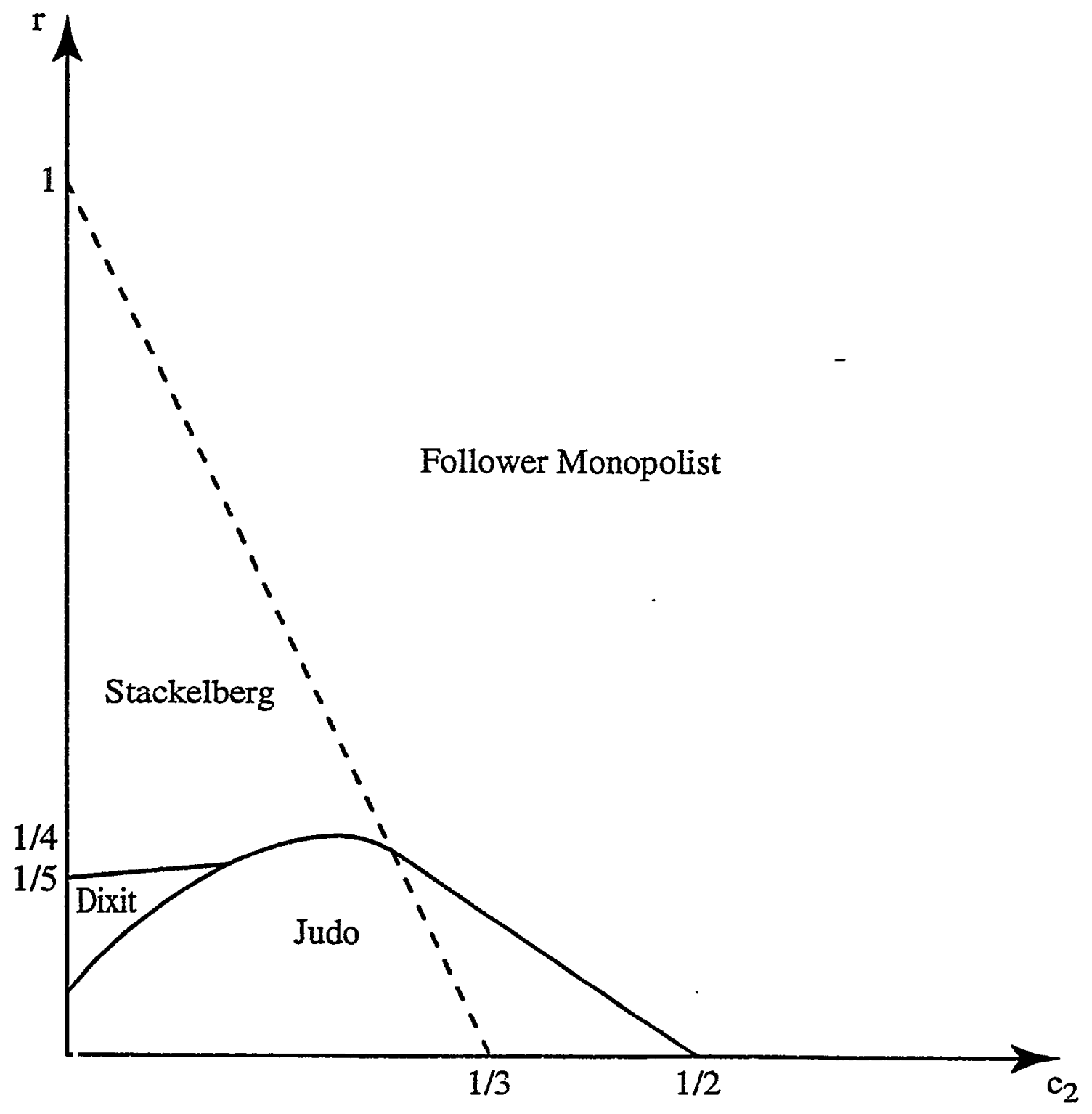

Figure $6 b$.

Nature of the Equilibrium in the Game $\Gamma\left(0, c_{2}, r, 0\right)$. 


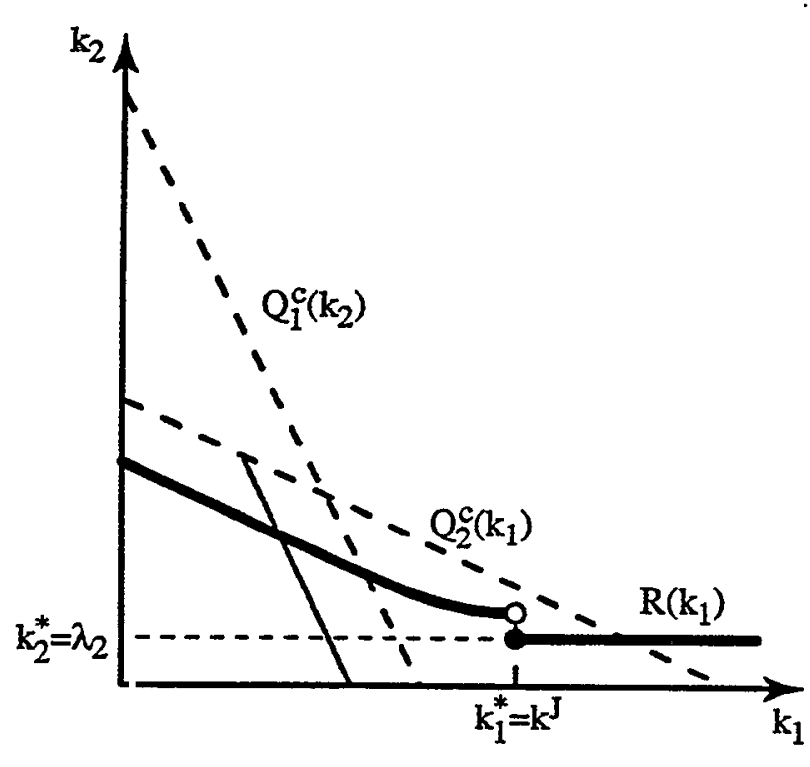

(a)

Entry Accomodation

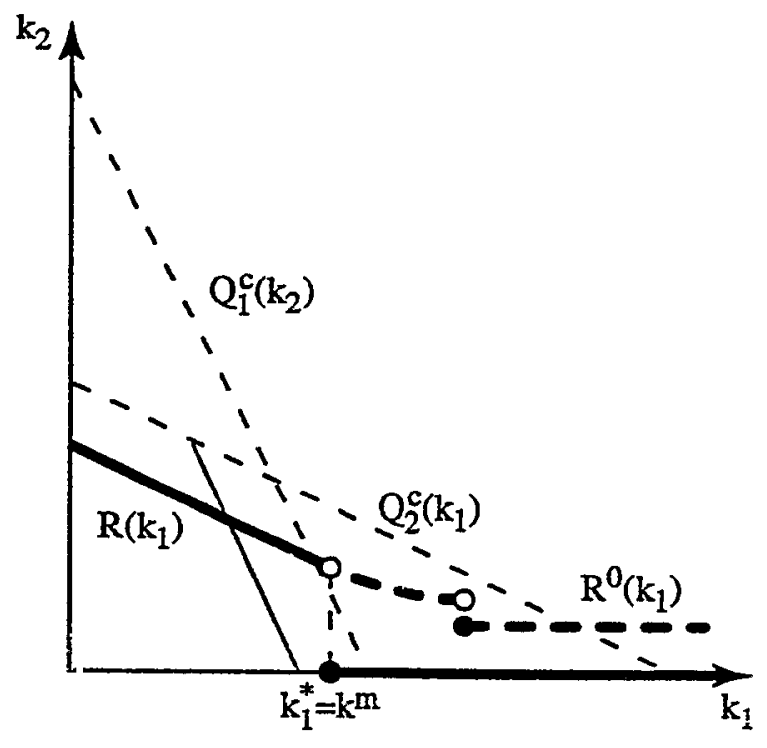

(c)

Deterrence with Excess (but not Idle) Capacity

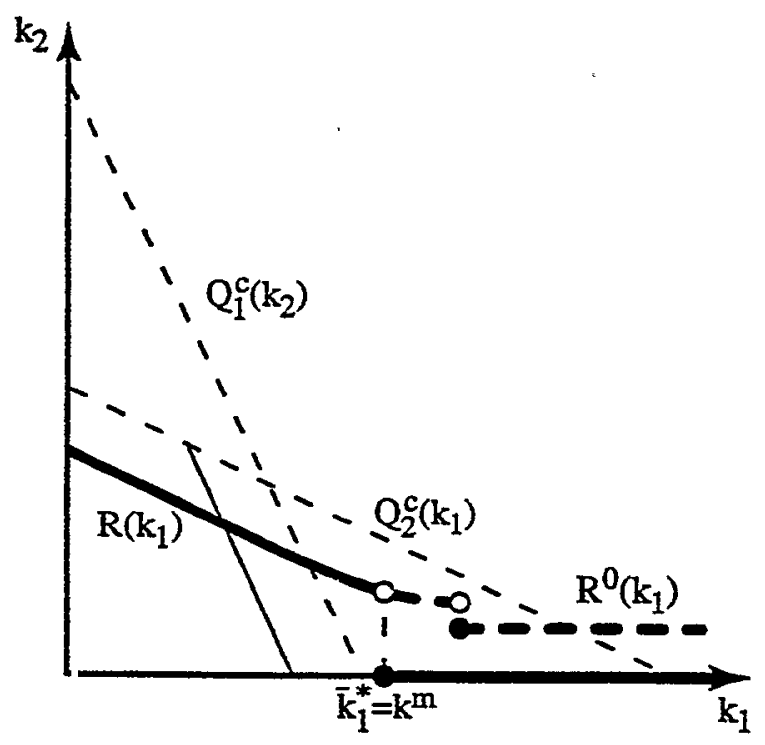

(b)

Deterrence with Idle Capacity

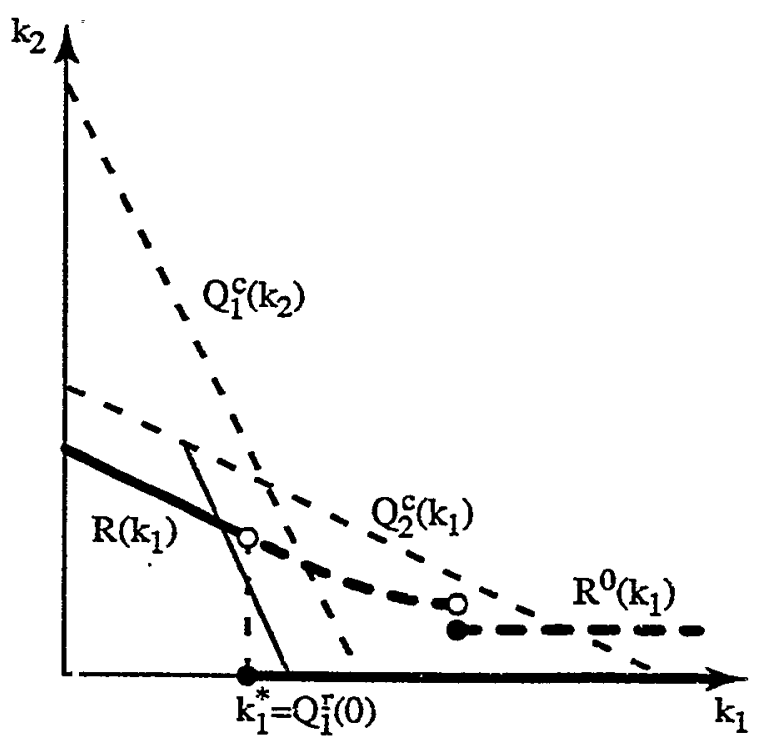

(d)

Blockaded Entry

Figure 7.

The Incumbent's Optimal Capacity Choice when Fixed Costs are Positive. 


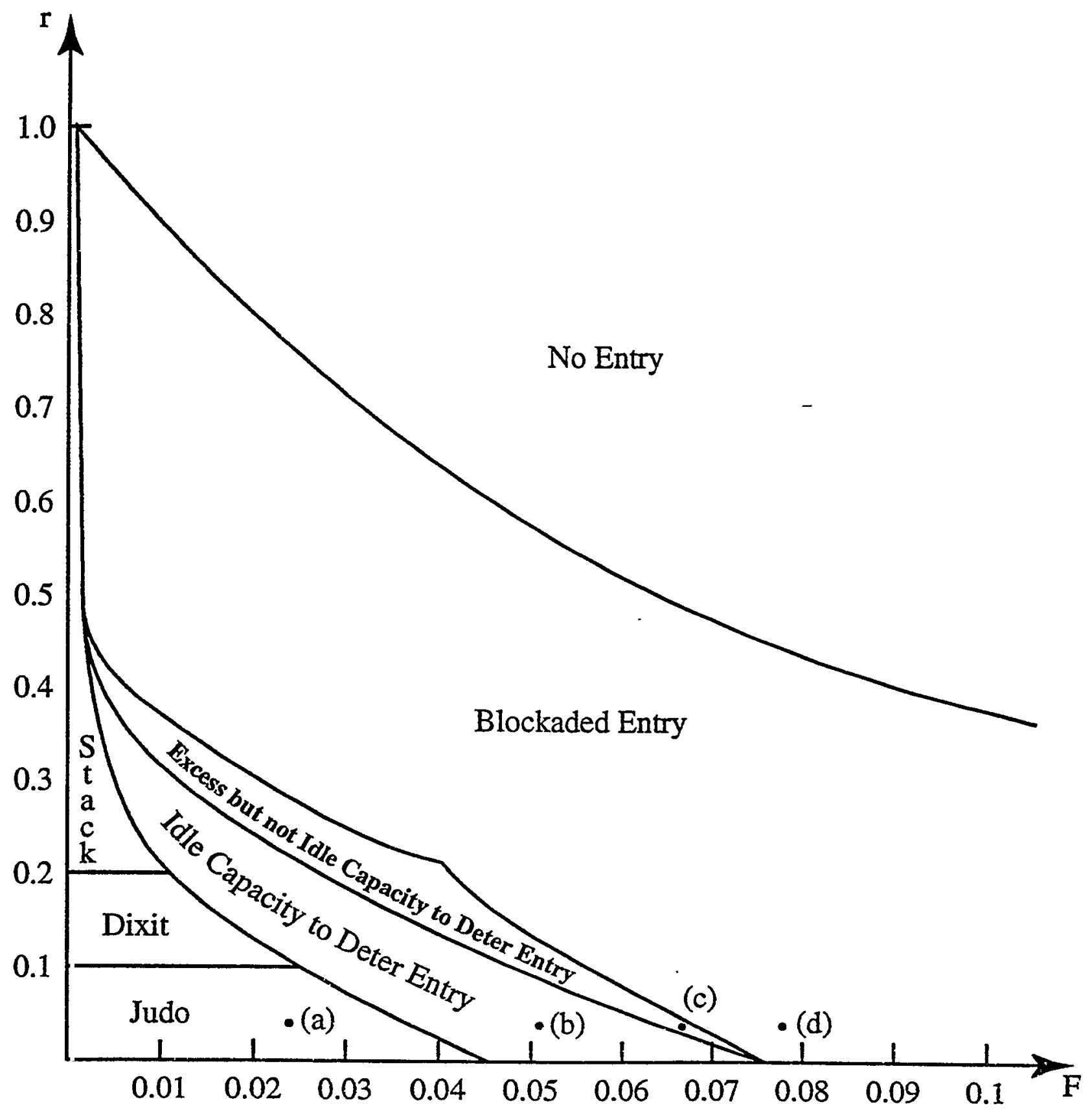

Figure 8.

Nature of the Equilibrium in the Game $\Gamma(0,0, \mathrm{r}, \mathrm{F})$. 


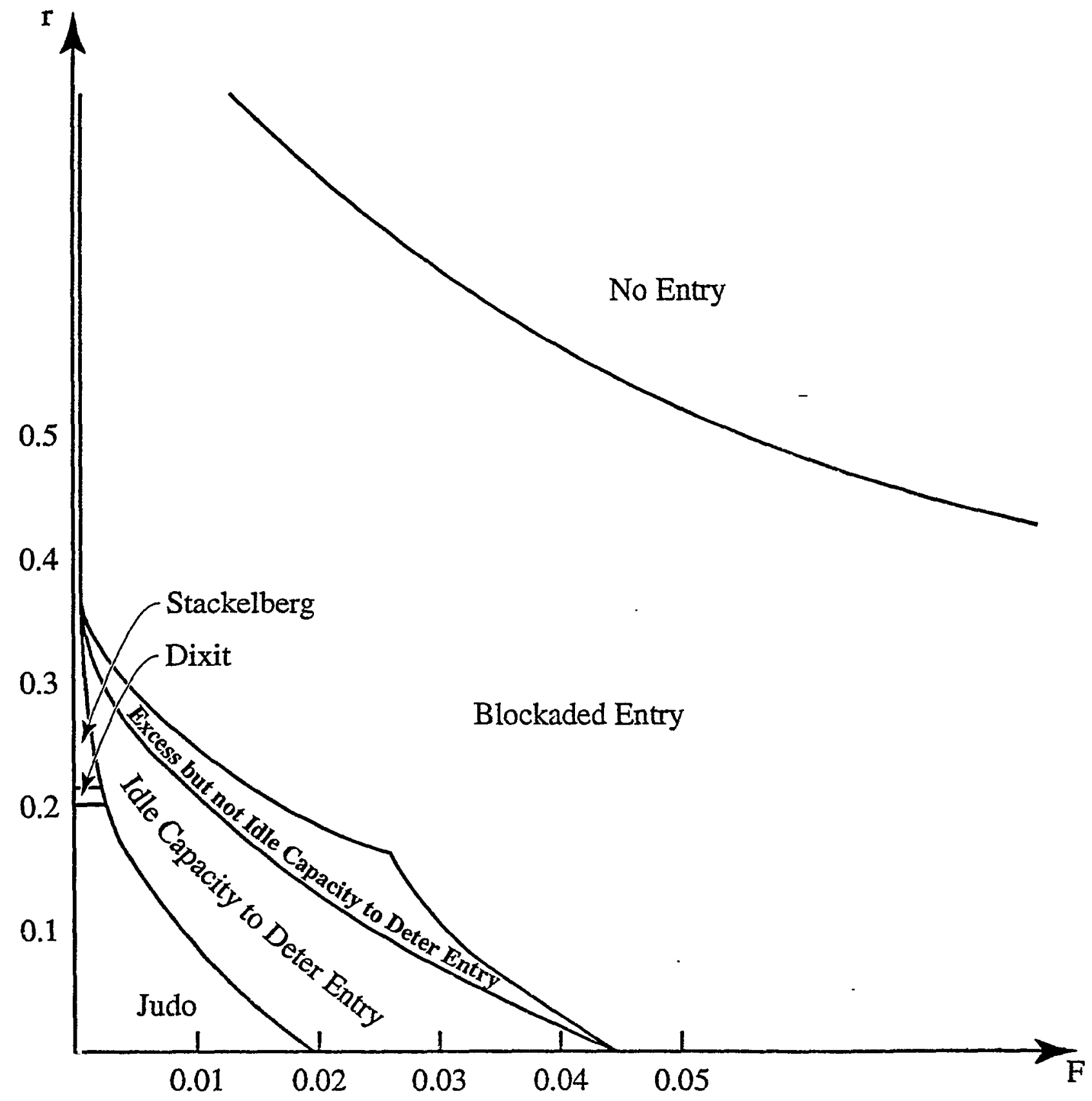

Figure 9.

Nature of the Equilibrium in the Game $\Gamma(0,0.1, \mathrm{r}, \mathrm{F})$. 


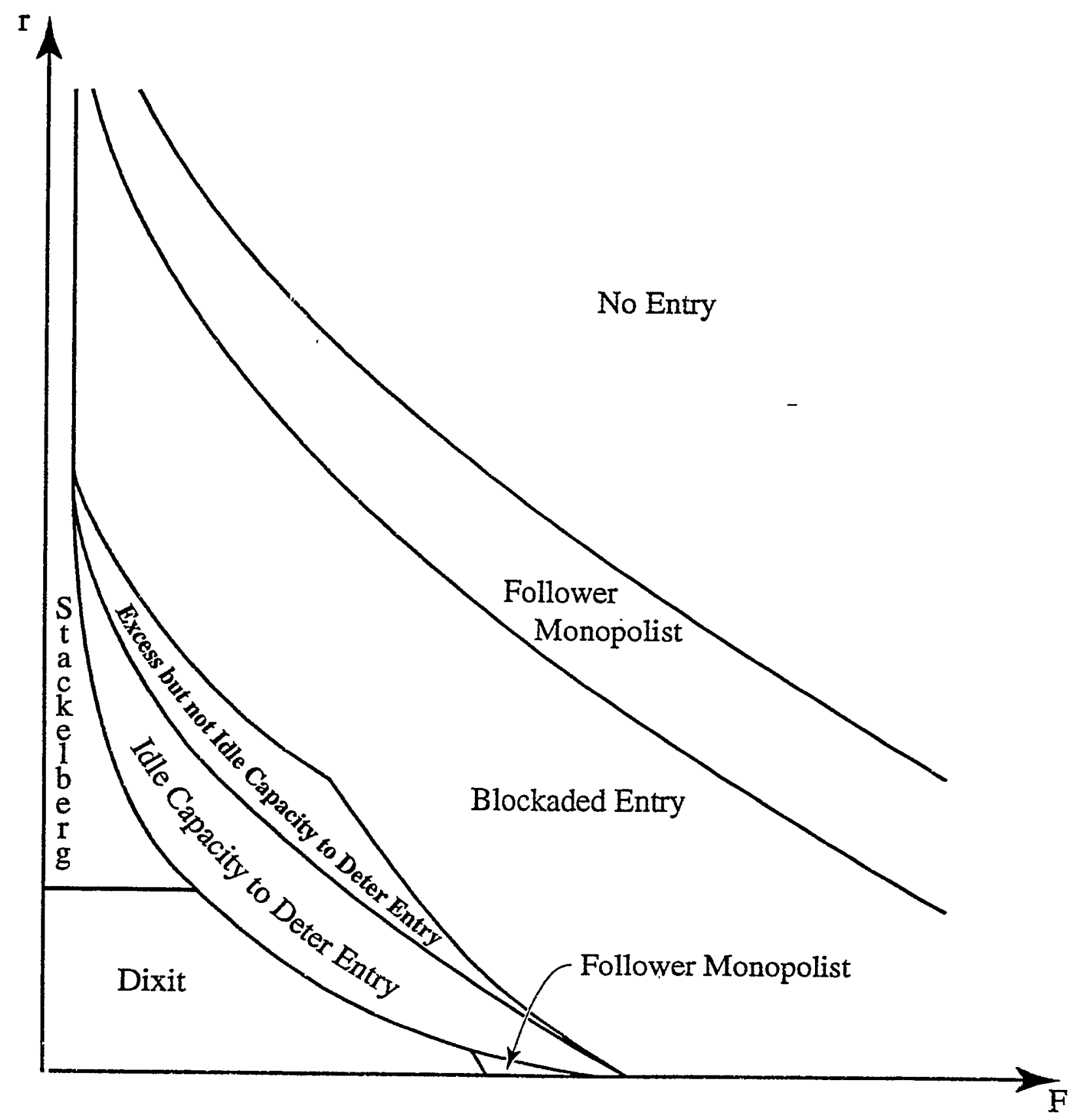

Figure 10.

Nature of the Equilibrium in the Game $\Gamma(0.1,0, \mathrm{r}, \mathrm{F})$. 


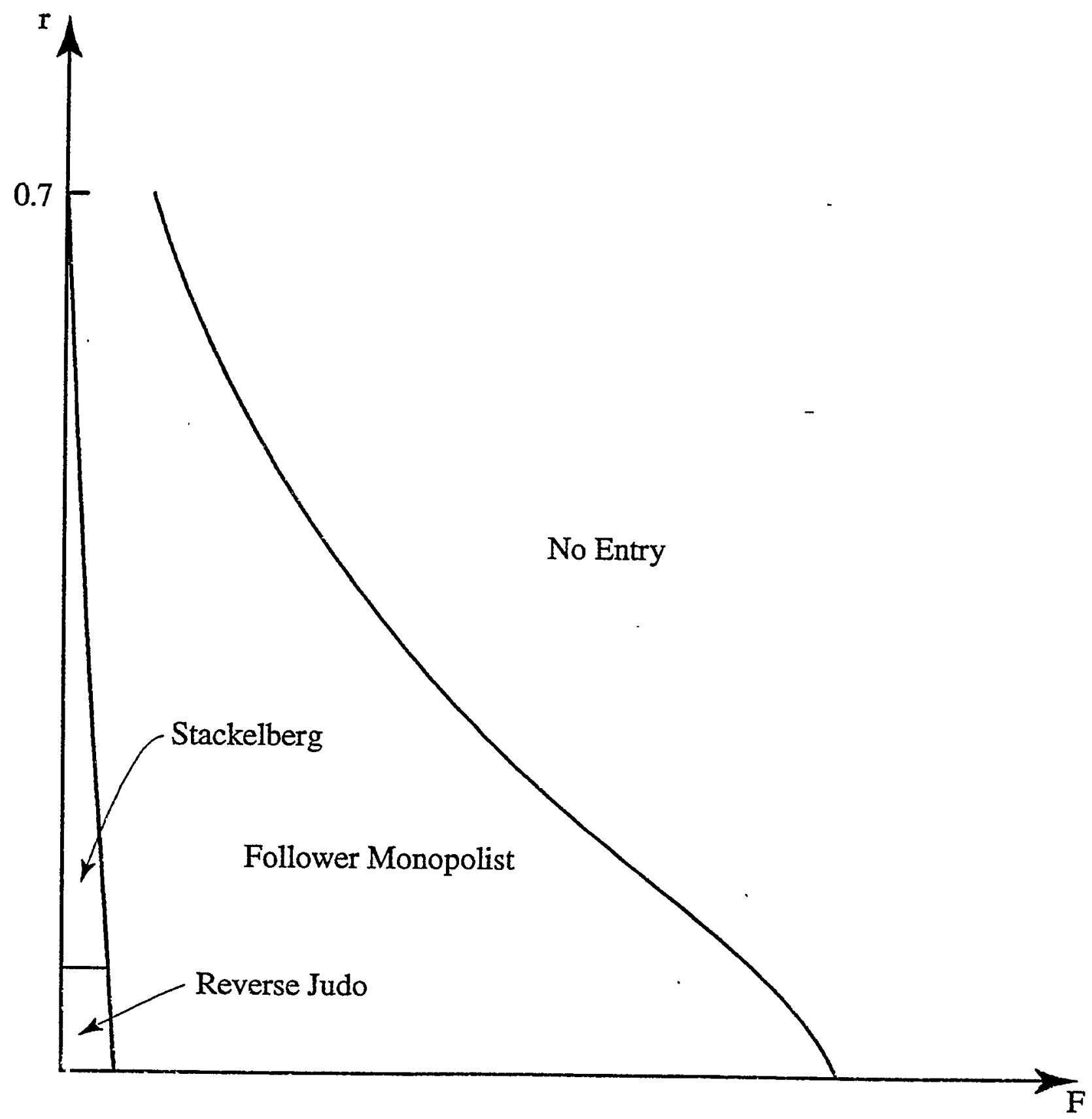

Figure 11.

Nature of the Equilibrium in the Game $\Gamma(0.3,0, r, F)$. 


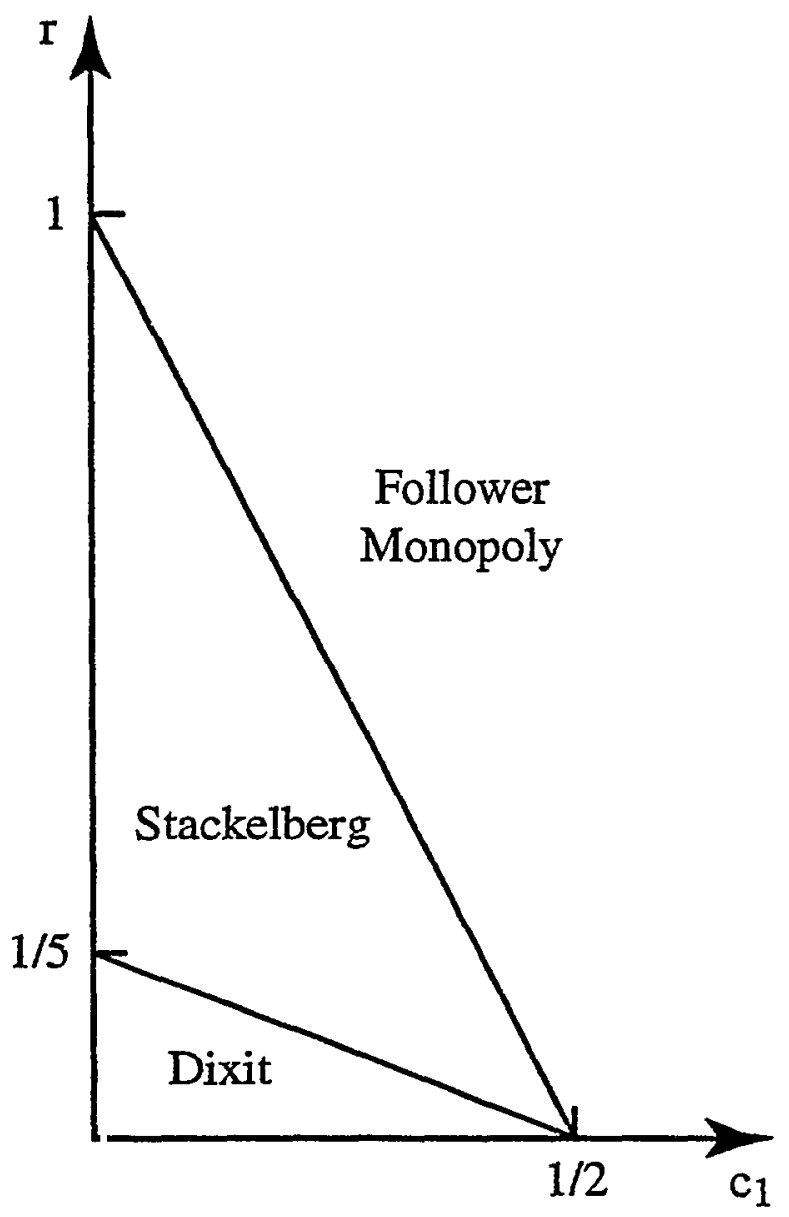

(a)

Quantity-Setting Behavior (as in Dixit (1979))

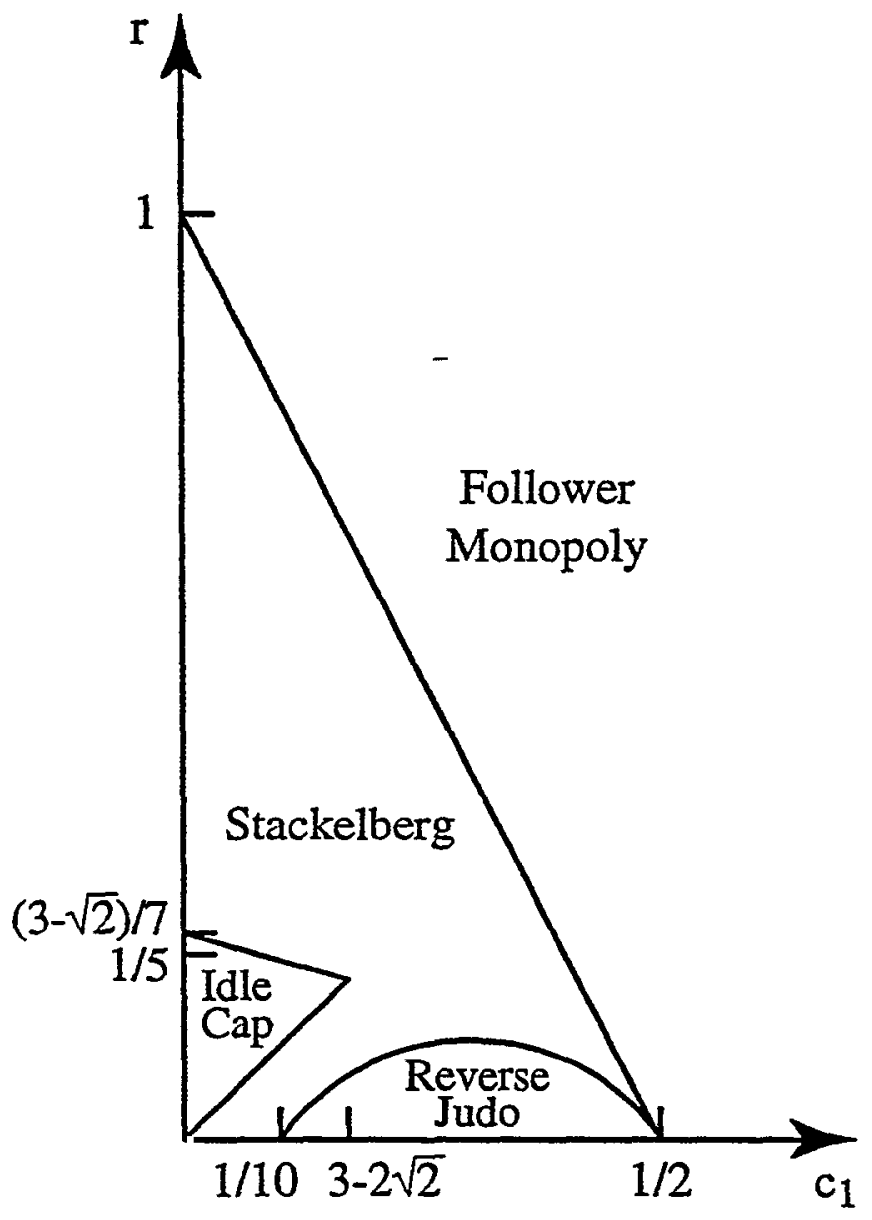

(b)

Price-Taking Behavior

Figure 12.

Nature of the Equilibrium of the Capacity Precommitment Game with Alternative Assumptions on Post-Entry Competition $\left(\mathrm{F}=\mathrm{c}_{2}=0\right)$. 


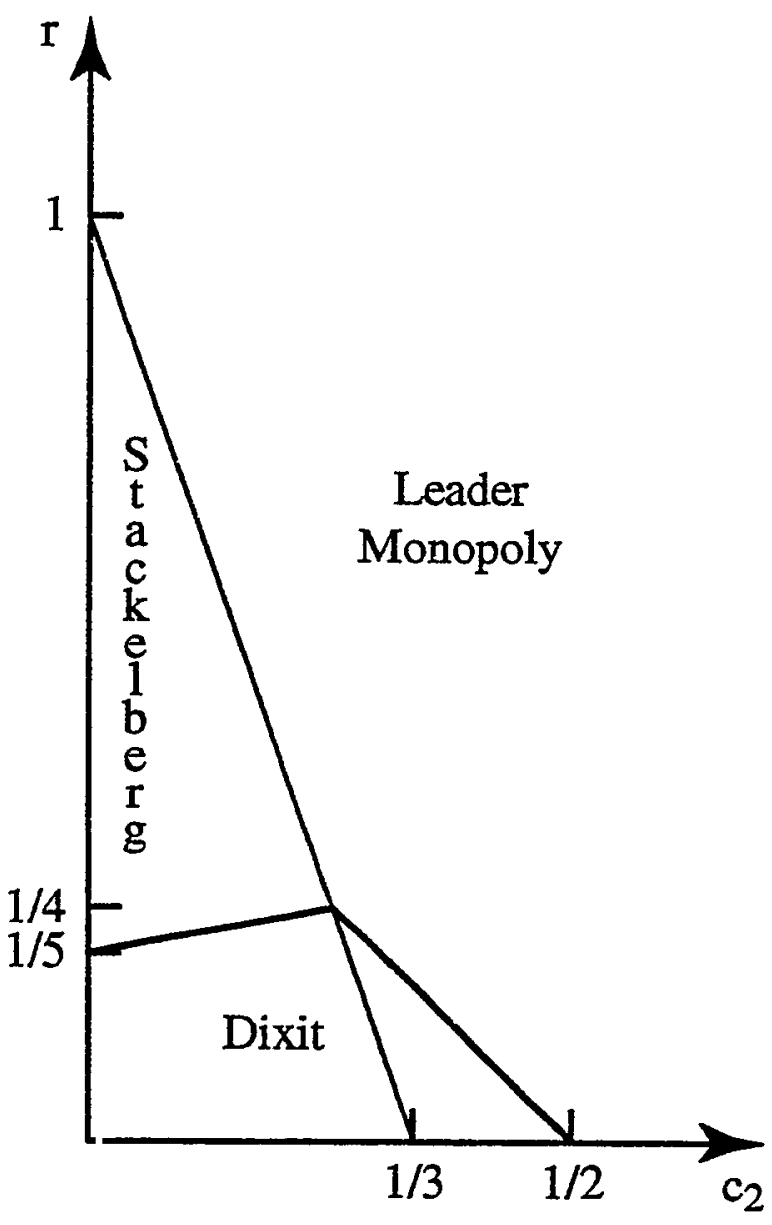

(a)

Quantity-Setting Behavior (as in Dixit (1979))

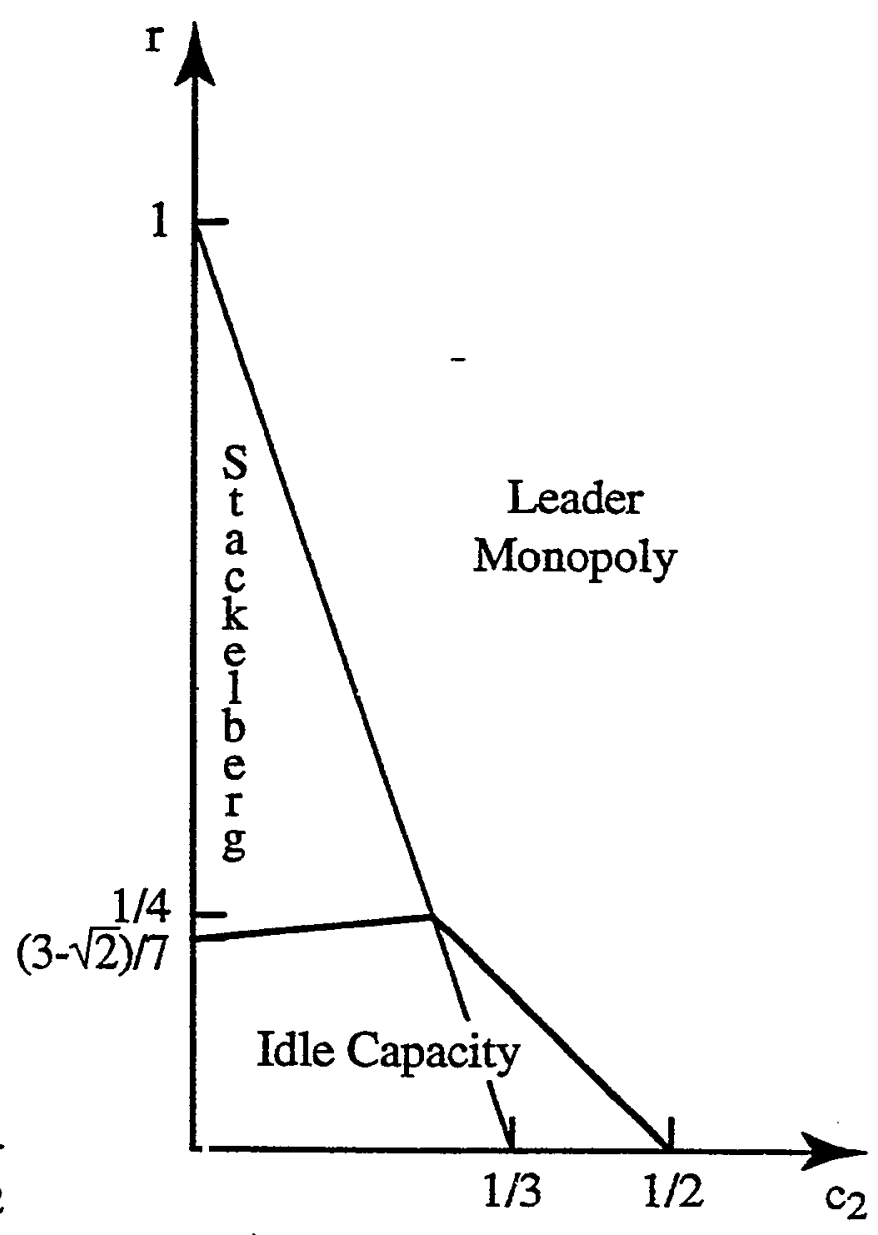

(b)

Figure 13.

Nature of the Equilibrium of the Capacity Precommitment Game with Alternative Assumptions on Post-Entry Competition $\left(F=c_{1}=0\right)$. 


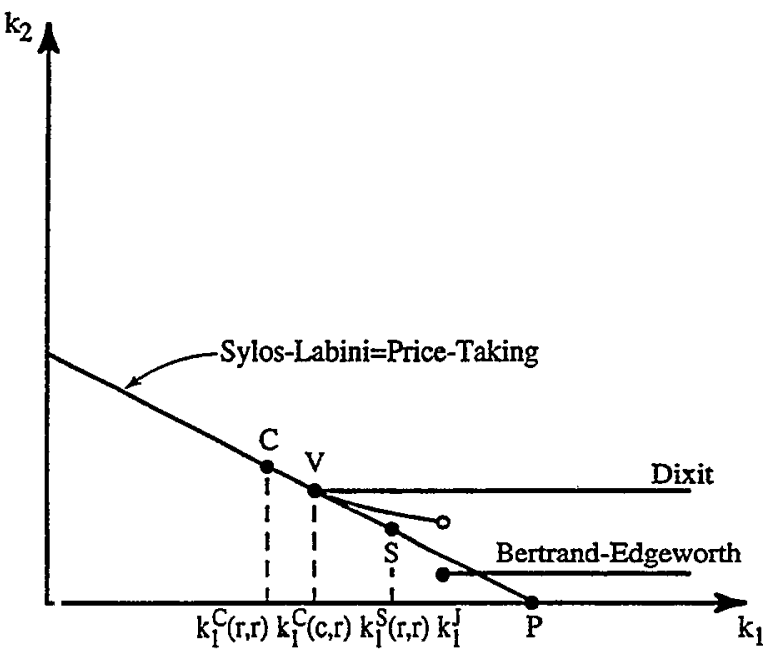

(a)

Parameter Values such that the Equilibrium of $\Gamma$ Falls in the Judo Region of Figure $6 b$.

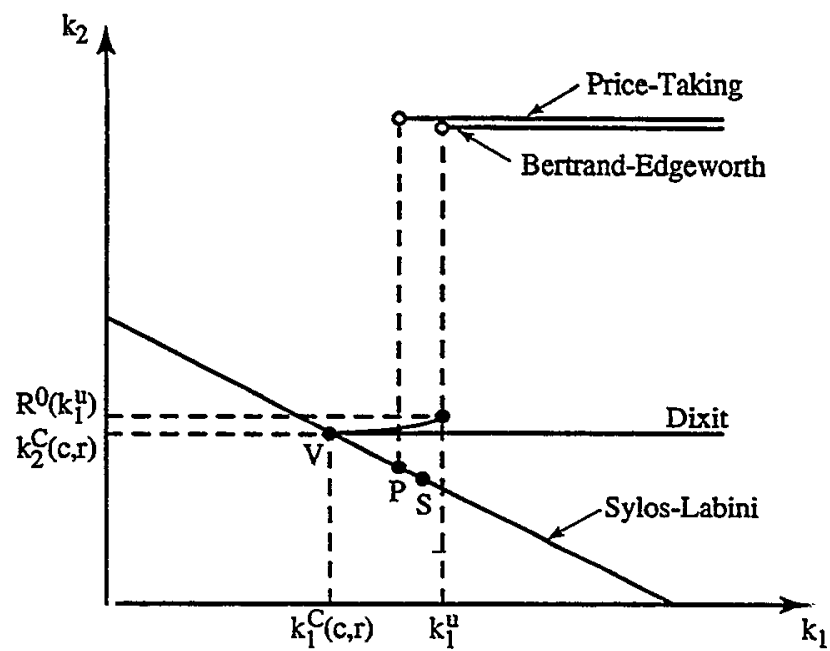

(b)

Parameter Values such that the Equilibrium of $\Gamma$ Falls in the Dixit Region of Figure $6 \mathrm{a}$.

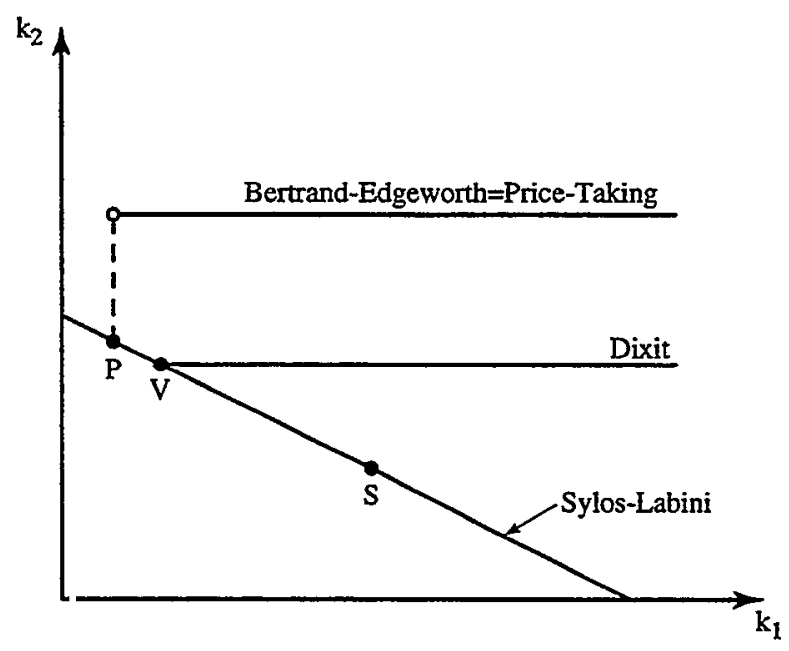

(c)

Parameter Values such that the Equilibrium of

$\Gamma$ Falls in the Reverse Judo Region of Figure 6a.

Figure 14.

A Comparison of the Capacity Best-Response Functions in Different Precommitment Games. The Equilibrium Outcomes on Each Best-Response Function are Denoted by a Bullet. 